\title{
Beyond the Myths of Coping with Loss: \\ Prevailing Assumptions \\ Versus Scientific Evidence
}

The death of a loved one is a ubiquitous human experience and is often regarded as a serious threat to health and well-being. Coming to terms with personal loss is considered to be an important part of successful adult development (Baltes \& Skrotzki, 1995). In this chapter, we draw from our own research and that of others to explore how people are affected by the death of a loved one. In our judgment, such losses provide an excellent arena in which to study basic processes of stress and adaptation to change. Unlike many stressful life experiences, bereavement cannot be altered by the coping efforts of survivors. Indeed, the major coping task faced by the bereaved is to reconcile themselves to a situation that cannot be changed and find a way to carry on with their own lives. By learning more about how people react to a loved one's death, and how they come to terms with what has happened, we can begin to clarify the theoretical mechanisms through which major losses can have deleterious effects on subsequent mental and physical health.

In our judgment, one of the most fascinating things about studying bereavement is the extraordinary variability that has been found regarding how people react to the death of a loved one. Some people are devastated and never again regain their psychological equilibrium; others emerge from the loss relatively unscathed and perhaps even strengthened (Elison \& McGonigle, 2003; Parkes \& Weiss, 1983). Yet at this point, we know relatively little about the diverse ways that people respond to the loss of a loved one, and why some people react with intense and prolonged distress while others do not. Do people who have the most rewarding and satisfying relationships with their loved one suffer the most following the loved one's death? Or is it those with conflictual or ambivalent relationships who experience the most distress following the loss of a loved one, as clinicians have frequently argued (see, e.g., Freud, 1917/1957; Parkes \& Weiss, 1983; Rando, 1993). Among those who fail to show distress following the loss, is this best understood as denial, lack of attachment, or resilience in the face of loss?

Over the years, we carried out several systematic evaluations of common assumptions about coping with loss that appear to be held by professionals in the field as well as laypersons (Bonanno $\&$ Kaltman, 2001; Wortman \& Silver, 1987, 1989, 2001). We identified these assumptions by reviewing some of the most important theoretical models of the grieving process, such as Freud's (1917/1957) grief work perspective and Bowlby's (1980) early attachment model (see Bonanno \& Kaltman, 1999; 
Wortman \& Silver, 2001). In addition, we examined books and articles written by and for clinicians and other health care providers that describe the grieving process (see, e.g., Jacobs, 1993; Malkinson, Rubin, \& Witztum, 2000; Rando, 1993). Finally, we reviewed books and articles written by and for bereaved individuals themselves (e.g., Gowell, 1992; Sanders, 1999). The following assumptions were identified:

1. Bereaved persons are expected to exhibit significant distress following a major loss, and the failure to experience such distress tends to be seen as indicative of a problem (e.g., that the bereaved person will experience a delayed grief reaction).

2. Positive emotions are implicitly assumed to be absent during this period. If they are expressed, they tend to be viewed as an indication that people are denying or covering up their distress.

3. Following the loss of a loved one, the bereaved must confront and "work through" their feelings about the loss. Efforts to avoid or deny feelings are maladaptive in the long run.

4. It is important for the bereaved to break down their attachment to the deceased loved one.

5. Within a year or two, the bereaved will be able to come to terms with what has happened, recover from the loss, and resume their earlier level of functioning.

Because these assumptions about the grieving process seemed to be firmly entrenched in Western culture, we anticipated that they would be supported by the available data. However, our reviews provided little support for any of these assumptions. For this reason, we labeled them "myths of coping with loss."

Initially, studies in the field of grief and loss were plagued by major methodological shortcomings, including the use of convenience samples, low response rates, attrition, and the failure to include control respondents. There was a dearth of scientific evidence on important concepts like "working through" and recovery from loss. Hence, in our earliest papers discussing these assumptions (Wortman \& Silver, 1987, 1989), it was difficult to evaluate the validity of some of them. Over the past few decades, however, research on bereavement has burgeoned. In fact, just in the last 10 years, approximately 5,000 articles have appeared on grief and/ or bereavement. In addition to a large number of sound empirical studies, two editions of an influential handbook of bereavement have appeared in the literature (Stroebe, Hansson, Stroebe, \& Schut, 2001; Stroebe, Stroebe, \& Hansson, 1993). As a result of the accumulation of research evidence, as well as related theoretical developments in the field of bereavement, some shifts have occurred in prevailing views about how people cope with the loss of a loved one. In this chapter, we review these developments.

In the first section of the chapter, we provide a brief review of the most influential theories of grief and loss, some of which have contributed to the myths of coping, while others have helped generate new questions about the grieving process. In the second section, we discuss each myth of coping, summarizing available evidence and highlighting ways the myths have changed over time as research evidence has accumulated. In these sections, we also identify what we believe to be the most important new areas of research. In the final section, we discuss the implications of this work for researchers, clinicians, and the bereaved themselves. In so doing, we consider the efficacy of grief counseling or therapy. We also address the question of what physicians, funeral directors, employers, and friends can do to support the bereaved in their efforts to deal with the loss.

\section{Theories of Grief and Loss}

Many different theoretical formulations have influenced the current understanding of the grief process (for a more detailed review, see Archer, 1999; Bonanno \& Kaltman, 1999; Rando, 1993; Stroebe $\&$ Schut, 2001).

\section{Classic Psychoanalytic View}

One of the most influential approaches to loss has been the classic psychoanalytic model of bereavement, which is based on Freud's (1917/1957) seminal paper, "Mourning and Melancholia." According to Freud, the primary task of mourning is the gradual surrender of psychological attachment to the deceased. Freud believed that relinquishment of the love object involves a painful internal struggle. The 
individual experiences intense yearning for the lost loved one yet is faced with the reality of that person's absence. As thoughts and memories are reviewed, ties to the loved one are gradually withdrawn. This process, which requires considerable time and energy, was referred to by Freud as "the work of mourning." At the conclusion of the mourning period, the bereaved individual is said to have "worked through" the loss and to have freed himself or herself from an intense attachment to an unavailable person. Freud maintained that when the process has been completed, the bereaved person regains sufficient emotional energy to invest in new relationships and pursuits. This view of the grieving process has dominated the bereavement literature over much of the past century and only more recently has been called into question (Bonanno \& Kaltman, 1999; Stroebe, 1992-1993; Wortman \& Silver, 1989). For example, it has been noted that the concept of grief work is overly broad and lacks clarity because it fails to differentiate between such processes as rumination, confrontative coping, and expression of emotion (Stroebe \& Schut, 2001).

\section{Attachment Theory}

Another theoretical framework that has been extremely influential is Bowlby's attachment theory (Bowlby, 1969, 1973, 1980; see also Fraley \& Shaver, 1999; Shaver \& Tancredy, 2001). In this work, Bowlby integrated ideas from psychodynamic thought, from the developmental literature on young children's reactions to separation, and from work on the mourning behavior of primates. Bowlby maintained that during the course of normal development, individuals form instinctive affectional bonds or attachments, initially between child and parent and later between adults. He believed that the nature of the relationship between a child and his or her mother or caregiver has a major impact on subsequent relationships. He suggested that when affectional bonds are threatened, powerful attachment behaviors are activated, such as crying and angry protest. Unlike Freud, Bowlby believed that the biological function of these behaviors is not withdrawal from the loved one but rather reunion. However, in the case of a permanent loss, the biological function of assuring proximity with attachment figures becomes dysfunctional. Consequently, the bereaved person struggles between the opposing forces of activated attachment behavior and the reality of the loved one's absence.
Bowlby maintained that in order to deal with these opposing forces, the mourner goes through four stages of grieving: initial numbness, disbelief, or shock; yearning or searching for the lost person, accompanied by anger and protest; despair and disorganization as the bereaved gives up the search, accompanied by feelings of depression and hopelessness; and reorganization or recovery as the loss is accepted, and there is a gradual return to former interests. By emphasizing the survival value of attachment behavior, Bowlby was the first to give a plausible explanation for responses such as searching or anger in grief. Bowlby was also the first to maintain that there is a relationship between a person's attachment history and how he or she will react to the loss of a loved one. For example, children who endured frequent separations from their parents may form anxious and highly dependent attachments as adults, and may react with intense, and prolonged grief when a spouse or partner dies (see Shaver \& Tancredy, 2001, or Stroebe, Schut, $\&$ Stroebe, 2005a, for a more detailed discussion). Because it provides a framework for understanding individual differences in response to loss, Bowlby's attachment model has continued to be influential in the study of grief and loss.

\section{Stages of Grief}

Another aspect of Bowlby's work that has been influential in determining how we think about grief is his idea that grieving involves stages of reaction to loss. Several theorists have proposed that people go through stages or phases in coming to terms with loss (see, e.g., Horowitz, 1976, 1985; Ramsay \& Happee, 1977; Sanders, 1989). Perhaps the most well known of these models is the one proposed by Kübler-Ross (1969) in her highly influential book On Death and Dying. This model, which was developed to explain how dying persons react to their own impending death, posits that people go through denial, anger, bargaining, depression, and ultimately acceptance. It is Kübler-Ross's model that popularized stage theories of bereavement. For many years, stage models have been taught in medical, nursing, and social work schools, and in many cases, these models firmly entrenched among health care professionals. Kübler-Ross's model has also appeared in articles in newspapers and magazines written for bereaved persons and their family members. As a result, stage models have strongly influenced the common understanding of grief in our society. 


\section{Beyond Stage Models}

As research has begun to accumulate, it has become clear that there is little support for the view that there are systematic stages. In contrast, the evidence shows that the reaction to loss varies considerably from person to person, and that few people pass through the stages in the expected fashion (see Archer, 1999, or Attig, 1996, for a review). Several major weaknesses of stage models have been identified. First, they cannot account for the variability in response that follows a major loss. Second, they place grievers in a passive role. Third, such models fail to consider the social or cultural factors that influence the process. Fourth, stage models focus too much attention on emotional responses to the loss and not enough on cognitions and behaviors. Finally, stage models tend to pathologize people who do not pass through the stages (Neimeyer, 1998). If people do not reach a state of acceptance, for example, they may be led to believe that they are not coping appropriately with the loss. As a result of these and other critiques and an absence of empirical support, most researchers have come to believe that the idea of a fixed sequence of stages is not particularly useful (Stroebe, Hansson, et al., 2001)

More recent theoretical models, such as Neimeyer's model of meaning reconstruction (Neimeyer, 1997, 1999), have attempted to address these shortcomings by portraying grief as a more idiosyncratic process in which people strive to make sense of what has happened. For example, Neimeyer $(2000,2006)$ has maintained that major losses challenge a person's sense of identity and narrative coherence. Narrative disorganization can range from relatively limited and transient to more sweeping and chronic, depending on the nature of the relationship and the circumstances surrounding the death. According to Neimeyer, a major task of grief involves reorganizing one's life story to restore coherence and maintain continuity between the past and the future.

\section{Stress and Coping Approach}

Over the past two decades, a theoretical orientation referred to as the stress and coping approach, or the cognitive coping approach (Lazarus \& Folkman, 1984; see also Carver, this volume), has become highly influential in the field of bereavement. Stress and coping theorists maintain that life changes like the death of a loved one become distressing if a person appraises the situation as taxing or exceeding his or her resources. An important feature of this model is that it highlights the role of cognitive appraisal in understanding how people react to loss. A person's appraisal, or subjective assessment of what has been lost, is hypothesized to influence his or her emotional reaction to the stressor and the coping strategies that are employed. As Folkman (2001) has indicated, however, there is surprisingly little research on specific coping strategies that people use to deal with loss and the impact of these various strategies. To explain why a given loss has more impact on one person than another, stress and coping researchers have focused on the identification of potential risk or protective factors, such as a history of mental health problems, optimism, social support, or financial assets (see Stroebe $\&$ Schut, 2001, for a review). The appraisal of the loss, as well as the magnitude of physical and mental health consequences that result from the loss, are thought to depend on these factors. Those with fewer risk factors, and more coping resources, are expected to recover more quickly and completely. Originally, the model focused primarily on negative emotions that were generated as a result of experiencing a stressful life event. In an important revision of the model, Folkman (2001) has incorporated positive emotions, which are believed to sustain coping efforts over time.

\section{Toward More Comprehensive Models of Bereavement}

Stage models and the stress and coping model can be applied to bereavement, but they were not developed specifically to account for people's reactions to the loss of a loved one. Within the past few years, two new theoretical models have been developed: Bonanno's four-component model (Bonanno \& Kaltman, 1999), and Stroebe and Schut's (1999, 2001) dual-process model. Not only do these models focus specifically on bereavement, but each attempts to integrate elements from diverse theoretical approaches into a comprehensive model. Bonanno's goal was to develop a conceptually sound and empirically testable framework for understanding individual differences in grieving. He identified four primary components of the grieving process - the context in which the loss occurs (e.g., was it sudden or expected, timely or untimely); the subjective meanings associated with the loss; changes in 
the representation of the lost loved one over time (e.g., does the bereaved person maintain a continuing connection with the deceased?); and the role of coping and emotion regulation processes that can mitigate or exacerbate the stress of loss. Unlike most other models, Bonanno's model considers the social and functional aspects of emotion. In so doing, it makes the prediction that recovery is most likely when negative grief-related emotions are regulated or minimized and when positive emotions are instigated or enhanced (Bonanno, 2001). This hypothesis, which is diametrically opposed to what would be derived from the psychodynamic approach, has generated considerable interest and support in recent years.

The dual-process model of coping with bereavement (Stroebe \& Schut, 1999, 2001) indicates that following a loved one's death, bereaved people alternate between two different kinds of coping: loss-oriented coping and restoration-oriented coping. While engaged in loss-oriented coping, the bereaved person focuses on and attempts to process or resolve some aspect of the loss itself. Restoration-oriented coping involves attempting to adapt to or master the challenges inherent in daily life, including life circumstances that may have changed as a result of the loss. Stroebe and Schut (1999, 2001) have proposed that each of these coping orientations is associated with certain kinds of costs, and that by alternating between them, the costs of employing one strategy too long can be minimized. They have suggested that early in the process, most people focus primarily on loss-oriented coping but that over time, there is a shift to more restorationoriented coping. They have also maintained that the model provides a way to understand individual differences in coping. For example, they pointed out that there is considerable evidence to indicate that women tend to be more loss-oriented than men (Stroebe \& Schut, 2001), thus suggesting a possible explanation for gender differences in response to loss. As Archer (1999) has noted, one of the most important features of this model is that it provides an alternative to the view that grief is resolved solely through confrontation with the loss.

Throughout the years, the theoretical models discussed here have influenced and, at the same time, have been influenced by the empirical work on coping with loss. For example, accumulating evidence regarding variability in response to loss led researchers to move away from traditional grief models and instead employ a stress and coping framework that can account for divergent responses to loss. In return, the empirical evidence that has come out of this effort to account for variability in response to loss has led to further theoretical development. For example, the most recent bereavement models have incorporated new insights about what questions are important to study and allow specific predictions as to how to address these questions. The following sections provide a review of the empirical work that in some ways has been the "engine" behind recent changes in our thinking about bereavement.

\section{Revisiting the "Myths of Coping"}

Over the past decade, bereavement research has continued to become more methodologically sophisticated, with many researchers employing powerful longitudinal designs to study the impact of loss. Some longitudinal studies have examined the reactions of the bereaved from a few months after the loss through the first 5 years (e.g., Bonanno, Keltner, Holen, \& Horowitz, 1995; Murphy, Johnson, Chung, \& Beaton, 2003; Murphy, Johnson, \& Lohan, 2002). Others have focused on people whose loved one is ill, and have assessed relevant variables before and at various intervals after the death (e.g., Folkman, Chesney, Collette, Boccellari, \& Cooke, 1996; Nolen-Hoeksema \& Larson, 1999; NolenHoeksema, McBride, \& Larson, 1997; Schulz, Mendelson, \& Haley, 2003). Still others have followed large community samples across time and studied those who became bereaved during the course of the study (e.g., Bonanno et al., 2002; Carnelley, Wortman \& Kessler, 1999; Lichtenstein, Gatz, Pederson, Berg, \& McClearn, 1996; Mendes de Leon, Kasl, \& Jacobs, 1994). Most studies have relied solely on respondents' assessments of key variables such as depression. However, some have used clinical assessments, and a few have included nonverbal data (e.g., Bonanno \& Keltner, 1997) or assessments from others (e.g., Bonanno, Moskowitz, Papa, \& Folkman, 2005).

The vast majority of bereavement studies have focused on the loss of a spouse. In the past decade, however, important new studies have appeared on reactions to the loss of a child (e.g., Dyregrov, Nordanger, \& Dyregrov, 2003; Murphy, 1996; Murphy et al., 1999; Murphy, Johnson, \& Lohan, 
2003); parent (e.g., Silverman, Nickman, \& Worden, 1992); and sibling (e.g., Balk, 1983; Batten \& Oltjenbruns, 1999; Cleiren, 1993; Hogan \& DeSantis, 1994). In one study, reactions to various kinds of familial loss were compared (Cleiren, 1993; Cleiren, Diekstra, Kerkhof, \& van der Wal, 1994). Most studies have focused on respondents who are heterogeneous with respect to cause of death. However, some have examined reactions to specific losses, such as parents whose children experienced a sudden, traumatic death (e.g., Dyregrov et al., 2003; Murphy, Johnson, \& Lohan, 2003), or gay male caregivers whose partners died of AIDS (e.g., Folkman, 1997a; Folkman et al., 1996; Moskowitz, Folkman, \& Acree, 2003; Moskowitz, Folkman, Collette, \& Vittinghoff, 1996). A few studies have compared two or more groups of respondents who lost loved ones under different circumstances (e.g., natural causes, accident, or suicide; e.g., Cleiren, 1993; Dyregrov et al., 2003; Middleton, Raphael, Burnett, \& Martinek, 1998; Murphy, Johnson, Wu, Fan, \& Lohan, 2003). Consequently, it is now possible to determine whether the "myths of coping" hold true across different kinds of deaths that occur under varying conditions. Of course, there are still some areas where relatively little is known. For example, the vast majority of studies on the loss of a spouse focus on middle-aged or elderly white women. This is ironic, since the available evidence (see, e.g., Miller \& Wortman, 2002; Stroebe, Stroebe, $\&$ Schut, 2001) suggests that men are more vulnerable to the effects of conjugal loss than are women. In recent years, there has been increasing interest in how men grieve (see, e.g., Martin \& Doka, 2000), and in gender differences in grieving (see, e.g., Wolff $\&$ Wortman, 2006; Wortman, Wolff, \& Bonanno, 2004). There are very few studies on reactions to the death of a sibling, despite evidence that this is a profound loss, particularly for adult women (Cleiren, 1993). With few exceptions (e.g., Carr, 2004), there is also a paucity of studies that include Blacks or Hispanics. Hence, it is difficult to determine whether the findings reported in the literature will generalize to these or other culturally diverse groups.

In the material to follow, each assumption about coping with loss is discussed in some detail. As we will show, beliefs about some of these assumptions have shifted over time as the evidence has continued to accumulate. For example, because several studies have identified a variety of common grief patterns among the bereaved, researchers have be- come more skeptical about the assumption that most people go through a period of intense distress following a loss. In the discussion to follow, each myth is updated, the available evidence is presented, and gaps in our knowledge base are identified.

\section{The Expectation of Intense Distress}

\section{Description}

The most prevalent theories in the area, such as classic psychoanalytic models (e.g., Freud, 1917/ 1957) and Bowlby's (1980) attachment model, are based on the assumption that at some point, people will confront the reality of their loss and go through a period of depression. Many books written by grief researchers, as well as those written by and for the bereaved, also convey the view that following the death of a loved one, most people react with intense distress or depression. For example, Sanders (1999) has maintained that once the bereaved person has accepted the reality of the loss, he or she will go through a phase of grief that can seem frightening "because it seems so like clinical depression" (p. 78). Similarly, Shuchter (1986) has indicated that "virtually everyone whose spouse dies exhibits some signs and symptoms of depression" (p. 170). It is anticipated that depression or distress will decrease over time as the bereaved comes to terms with the loss.

Historically, the failure to exhibit grief or distress following the loss of a spouse has been viewed as an indication that the grieving process has gone awry (e.g., Deutsch, 1937; Marris, 1958). Bowlby (1980) identified "prolonged absence of conscious grieving" (p. 138) as one of two possible types of disordered mourning, along with chronic mourning. Marris (1958) has indicated that "grieving is a process which 'must work itself out' . . if the process is aborted from too hasty a readjustment... the bereaved may never recover" (p. 33). In recent years, some investigators have challenged the assumption that the failure to experience distress is indicative of pathology. For example, M. Stroebe, Hansson, and Stroebe (1993) have argued that there are many possible reasons why a bereaved person may not exhibit intense distress that would not be considered pathological (e.g., early adjustment following an expected loss; relief that the loved one is no longer suffering).

However, available evidence suggests that most practicing clinicians continue to maintain, either 
explicitly or implicitly, that there is something wrong with individuals who do not exhibit grief or depression following the loss of a loved one. In a survey of expert clinicians and researchers in the field of loss (Middleton, Moylan, Raphael, Burnett, \& Martinek, 1993), a majority (65\%) endorsed the belief that "absent" grief exists, that it typically stems from denial or inhibition, and that it is generally maladaptive in the long run. An important component of this view is that it assumes that if people fail to experience distress shortly after a loss, problems or symptoms of distress will erupt at a later point. For example, Bowlby (1980) has argued that individuals who have failed to mourn may suddenly, inexplicably become acutely depressed at a later time (see also Rando, 1984; Worden, 2002). These authors have also maintained that the failure to grieve will result in subsequent health problems (Bowlby, 1980; Worden, 2002).

Consistent with the notion that "absent" grief signals unhealthy denial and repression of feelings, there is a great deal of clinical literature to suggest that people who have lost a loved one, but who have not begun grieving, will benefit from clinical intervention designed to help them work through their unresolved feelings (see, e.g., Bowlby, 1980; Deutsch, 1937; Jacobs, 1993; Lazare, 1989; Rando, 1993; Worden, 2002). In a report published by the Institute of Medicine, for example, Osterweis, Solomon, and Green (1984) concluded that "professional help may be warranted for persons who show no evidence of having begun grieving."(p. 136). Similarly, Jacobs (1993) has suggested that the bereaved individuals who experience "inhibited grief . . . ought to be offered brief psychotherapy by a skilled therapist" (p. 246).

The failure to exhibit distress following the loss of a loved one has also been viewed as evidence for character weakness in the survivor. In a classic paper, Deutsch (1937) maintained that grief-related affect was sometimes absent among individuals who were not emotionally strong enough to begin grieving. Osterweis et al. (1984) emphasized that clinicians typically assume "that the absence of grieving phenomena following bereavement represents some form of personality pathology" (p. 18). Similarly, Horowitz (1990) has stated that those who show little overt grief or distress following a loss are "narcissistic personalities" who "may be too developmentally immature to have an adult type of relationship and so cannot exhibit an adult type of mourning at its loss" (p. 301; see also Raphael, 1983). It has also been suggested that some people fail to exhibit distress because they were only superficially attached to their spouses (Fraley \& Shaver, 1999; Rando, 1993).

\section{Evidence for Intense Distress}

Among people who have experienced the loss of a loved one, is it true that distress is commonly experienced? Will distress or depression emerge at a later date among those who fail to exhibit distress in the first several weeks or months following the loss? We identified several studies that provide information bearing on these questions. Most of these studies focused on the loss of a spouse (Boerner, Wortman, \& Bonanno, 2005; Bonanno, Moskowitz, et al., 2005; Bonanno et al., 2002; Bonanno $\&$ Field, 2001; Bonanno et al., 1995; Bournstein, Clayton, Halikas, Maurice \& Robins, 1973; Lund et al., 1985-1986; Vachon, Rogers, et al., 1982; Vachon, Sheldon, et al., 1982; Zisook \& Shuchter, 1986); two examined reactions to the loss of a child (Bonanno, Moskowitz, et al., 2005; Wortman \& Silver, 1993); and another two focused on response to loss following a time of caregiving for a chronically ill loved one (Bonanno et al., in press; Schulz et al., 2003). These studies assessed depression or other forms of distress in the early months following the death, and then again anywhere from 13 to 60 months after the loss. The construct of depression/distress was operationalized differently in the different studies. For example, some studies utilized the SCL-90 depression subscale and/or DSM-based SCID (e.g., Bonanno, 2005); other studies used the CESD depression scale (e.g., Bonanno et al., 2002). For each study, the investigators determined a cutoff score to classify respondents as high or low in distress or depression.

The longitudinal studies identified here provide evidence regarding the prevalence of different patterns of grief. "Normal" or "common" grief, which involves moving from high distress to low distress over time, was found among $41 \%$ of participants in a study on loss of a child from SIDS (Wortman $\&$ Silver, 1987), and anywhere between 9\% and $41 \%$ in studies on conjugal loss (35\% in Bonanno et al., 1995; 29\% in Bournstein et al., 1973; 9\% in Lund, Caserta, \& Dimond, 1986; 41\% in Vachon, Rogers, et al., 1982; and 20\% in Zisook \& Shuchter, 1986). Furthermore, in these studies, evidence for "minimal" or "absent" grief, which involves scoring 
low in distress consistently over time, was found for 26\% (Wortman \& Silver, 1987), 41\% (Bonanno et al., 1995), 57\% (Bournstein et al., 1973), 30\% (Vachon, Rogers, et al., 1982), 78\% (Lund et al., 1986), and 65\% (Zisook \& Shuchter, 1986).

In a recent prospective study on conjugal loss among older adults that included data from 3 years pre-loss to 18 months postloss (Bonanno et al., 2002; Bonanno, Wortman, \& Nesse, 2004), nearly half of the participants (46\%) experienced low levels of distress consistently over time (i.e., resilient group), and only 11\% showed "normal" or "common" grief. Another trajectory in this study referred to as "depressed-improved" reflected elevated distress before the loss and improvement after the loss (10\%). A similar pattern of reduced distress levels following the loss was detected in a prospective study on caregivers of dementia patients that included both pre- and postloss data (Schulz et al., 2003).

Taken together, in all studies, less than half of the sample showed "normal" grief, and in many, such a reaction was shown by only a small minority of respondents. In fact, in the prospective study on conjugal loss by Bonanno et al. (2002), the relatively small proportion of those who showed "normal" grief (11\%) was almost equal to those who showed a depressed-improved pattern of being more distressed before the loss, followed by improvement after the loss (10\%). Most important, however, the available evidence shows that "minimal" or "absent" grief is very common. The number of respondents failing to show elevated distress or depression at the initial or final time point was sizable, ranging from one quarter of the sample to more than three quarters of the sample. In fact, a recent comparison of nonbereaved and bereaved individuals (who lost either a child or a spouse; Bonanno, Moskowitz, et al., 2005) showed that, in terms of distress levels, slightly more than half of the bereaved did not significantly differ from the matched sample of married individuals when assessed at 4 and 18 months postloss. It should be noted that category labels such "minimal" or "absent" grief do not mean that there was absolutely no distress at any moment after the loss, but rather that despite brief spikes in distress around the time of the death (Bonanno, Moskowitz et al., 2005) or a short period of daily variability in levels of wellbeing (Bisconti, Bergeman, \& Boker, 2004), people who showed these patterns had generally low distress levels and managed to function at or near their normal levels (Bonanno, 2005). The prevalence of the "minimal" or "absent" grief reaction alone calls into question the assumption that failure to show distress following a loss is pathological. In fact, it suggests that learning more about why many people do not exhibit significant distress following a loss should become an important research priority.

\section{Studies with Assessment of Mild Depression}

When we have described these findings in the past (e.g., Bonanno et al., 2002; Wortman \& Silver, 1989 , 2001), it was sometimes suggested that the data may underestimate those who show significant distress following a loss. This is because the studies we reviewed classify respondents as depressed only if their score exceeds a cutoff believed to reflect clinically significant levels of depression. Respondents who do not exhibit major depression may still be evidencing considerable distress or depression. The previous studies do not speak to this issue, since they do not include measures of mild depression.

Fortunately, such measures have been included in a number of more recent studies. For example, Bruce, Kim, Leaf, and Jacobs (1990) assessed dysphoria as well as depression in a study of conjugally bereaved individuals (aged 45 and older). Dysphoria was defined as feeling "sad, blue, depressed or when you lost all interest and pleasure in things you usually cared about or enjoyed" for 2 weeks or more. About $60 \%$ of the respondents had experienced dysphoria. However, a significant minority (almost 40\%) did not go through even a 2-week period of sadness following their loss. Similarly, Zisook, Paulus, Shuchter, and Judd (1997) conducted a study of elderly widowers and widows in which their ratings on symptom inventories were used to classify them into DSM-IV categories of major depression, minor depression, subsyndromal depression (endorsing any two symptoms from the symptom list), and no depression (endorsing one or no items reflecting depression). Two months after the partner's death, 20\% were classified as showing major depression, 20\% were classified as exhibiting minor depression, and $11 \%$ were classified as evidencing subsyndromal depression. Fortynine percent of the respondents were classified as evidencing no depression (see also Cleiren, 1993). These studies provide compelling evidence that 
following the death of a spouse, a substantial percentage of people do not show significant distress.

\section{Delayed Grief}

Is it true that if the bereaved do not become depressed following a major loss, a "delayed grief reaction," or physical health problems, will emerge at some point in the future? The data from the longitudinal studies we identified fail to support this view. In two studies, there were no respondents showing a delayed grief reaction (Zisook \& Shuchter, 1986; Bonanno et al., 1995; Bonanno \& Field, 2001). In the remaining studies, the percentage of respondents showing delayed grief was .02\%, $1 \%$, $2 \%, 2.5 \%$, and $5.1 \%$, respectively (Boerner et al., 2005; Bournstein et al., 1973; Lund et al., 1986; Wortman \& Silver, 1987; Vachon, Rogers, et al., 1982). It should be noted that in two of these studies (Lund et al., 1986; Zisook \& Shuchter, 1986), bereaved respondents were interviewed at frequent intervals during the course of the study. There were very few respondents who moved from low distress to high distress on any subsequent interview. These studies demonstrate that "delayed grief" does not occur in more than a small percentage of cases. Nor do physical symptoms appear to emerge among those who fail to experience distress soon after the loss. Both the Boerner et al. (2005) and Bonanno and Field (2001) studies are convincing on this point, because conjugally bereaved individuals were assessed over a 4- and 5-year period, respectively, using multiple outcome measures. Data failing to support the "delayed grief" hypothesis were also obtained by Middleton et al. (1996). Based on cluster analyses of several bereaved samples, she concluded that "no evidence was found for . . . delayed grief." Nonetheless, in the previously described survey conducted by Middleton et al. (1993), a substantial majority of researchers and clinicians (76.6\%) indicated that delayed grief does occur.

\section{Predictors of "Minimal" Distress}

The hypothesis that some people fail to become distressed following a loss because they were not attached to the loved one, or because they were cold and unfeeling, has only recently been subject to empirical research. Bonanno et al. (2002) tested the prediction that those who reported low levels of depression from pre-loss through 18 months of bereavement (resilient group) would score higher on pre-loss measures of avoidant/dismissive attachment than those in other groups (depressed-improved, common grief, chronic grief, and chronic depression). They also examined whether those in the resilient group would evaluate their marriage less positively and more negatively, and whether they would be rated by interviewers as less comfortable and skillful socially, and as exhibiting less warmth compared with the other groups at the pre-loss time point. The resilient group did not appear to differ from the other groups on any of these variables. A follow-up study yielded similar results with respect to variables on processing the loss (Bonanno et al., 2004). For example, the resilient group scored relatively high on comfort from positive memories of the deceased, a finding that also argues against the view that they were not strongly attached to the deceased. Furthermore, in their recent study on the loss of spouse or child, Bonanno, Moskowitz, et al. (2005) found that the friends of bereaved participants who showed resilience following the death rated them more positively, and reported having more contact and closer relations with them. Taken together, these findings do not support and even contradict the hypothesis that absence of intense distress following loss is a sign of lack of attachment to the deceased or the inability to maintain close relationships.

Thus, available evidence clearly indicates that the so-called normal grief pattern is not as common as was assumed in the past, and that a significant proportion of bereaved individuals experience relatively little distress following a loss, without showing delayed grief or other signs of maladjustment. It should be noted, however, that such a reaction is far more prevalent following some kinds of losses than others. For example, elderly people who lose a spouse are more likely to show consistently low distress than younger individuals who lose a spouse or parents who lose a child. In fact, research on the loss of a child under sudden or violent circumstances suggests that it is normative to experience intense distress following such a loss. In her study on the violent death of a child, for example, Murphy (1996) found that 4 months after the loss, more than $80 \%$ of the mothers and $60 \%$ of the fathers rated themselves as highly distressed. Thus, there is clear evidence that both the nature of the death and the circumstances surrounding the loss play a critical role in people's response to loss. These and 
other factors associated with long-term difficulties in adaptation to loss will be discussed in the section on recovery.

\section{Future Directions}

Given the prevalence of resilience or low distress following a loss, we need to learn more about the potential costs and benefits of this response. As described previously, there is evidence that for the bereaved person, resilience, or showing consistently low distress following the loss, appears to be an adaptive response. However, it would be interesting to address whether there are any disadvantages associated with resilience. For example, participants who showed the resilient pattern may have had a way of approaching life that made them less vulnerable to life stressors but also less attentive to others' concerns. If so, this could result in lower pre-loss marital satisfaction among their spouses. The best way to test these ideas would be to draw on prospective data of couples or multiple family members, in which each person's perspective on the relationship is assessed prior to the loss and at various points thereafter. Such data would provide the opportunity to learn what the deceased person thought about his or her relationship with the "resilient person."

A related important issue would be to consider the social implications of a resilient pattern in response to loss. In some cases, the resilient person may elicit negative reactions from others because others expect the bereaved to show more distress. Others may interpret low levels of distress as an indication of aloofness or indifference. In other cases, showing resilience may reflect positively on the bereaved because it is easier for others to be with a less distressed person. Another intriguing question is what happens in families or other social groups when one person shows a low distress pattern after a loss, whereas the other members in this social system experience intense distress. In such a case, would those who are more distressed be likely to benefit from the presence or availability of a resilient person? Or would the lack of congruence in the experience of individual members be more likely to lead to misunderstandings and individual coping efforts that interfere with one another? These questions are likely to assume considerable importance in couples following the death of a child. For example, one spouse may feel uncomfortable expressing feelings of distress about the loss if it ap- pears that the partner is not as distressed (e.g., Wortman, Battle, \& Lemkau, 1997). Future work addressing these questions would make an important contribution because people rarely face a loss in a social vacuum.

\section{Positive Emotions Are Typically Absent}

\section{Description}

The most important theories of grief and loss, such as Freud's (1917/1957) psychoanalytic model and Bowlby's (1980) attachment model, emphasize the importance of working through the emotional pain associated with the loss. Amid the despair and anguish that often accompany grief, positive emotions may seem unwarranted, even inappropriate (Fredrickson, Tugade, Waugh, \& Larkin, 2003). When they are mentioned at all, positive emotions are typically viewed as indicative of denial and as an impediment to the grieving process (Deutsch, 1937; Sanders, 1993; see Keltner \& Bonanno, 1997, for a review). With notable exceptions (e.g., Folkman, 1997b; Folkman \& Moskowitz, 2000; Fredrickson, 2001; Lazarus, Kanner, \& Folkman, 1980), theories focusing specifically on the grieving process, or more generally on coping with adversity, have failed to consider the role that may be played by positive emotions.

In the 1980s, Wortman and her associates became interested in whether positive emotions were experienced by people who had encountered major losses, and if so, whether they could perhaps sustain hope and facilitate adjustment. Therefore, they decided to measure positive as well as negative emotions in two studies, one focusing on permanent paralysis following a spinal cord injury, and one focusing on loss of a child as a result of sudden infant death syndrome (SIDS); see Wortman \& Silver, 1987, for a more detailed discussion). In conducting the first study, they encountered extreme resistance from the hospital staff, who felt it was "ridiculous" to ask people who were permanently disabled about their positive emotions. In the second study, they experienced similar problems from their interviewers, who did not want to ask people who had lost a child how many times they had felt happy in the past week. Only through careful pilot work and much persuading were they able to convince the staff, and the interviewers, that the project was indeed feasible and worthwhile. 


\section{Evidence for Positive Emotions Following Loss}

Both of these studies provided evidence that positive emotions are quite prevalent following major loss. At 3 weeks following the death of their infant to SIDS, parents reported experiencing positive emotions such as happiness as frequently as they experienced negative feelings. By the second interview, conducted 3 months after the infant's death, positive affect was more prevalent than negative affect, and this continued to be the case at the third interview, conducted at 18 months after the loss. Respondents were asked to describe the intensity as well as the frequency of their feelings. These measures were included so that the investigators could determine whether negative feelings, while no more prevalent than positive ones, were more intense. However, this did not turn out to be the case. At all three interviews, feelings of happiness were found to be just as intense as feelings of sadness. In fact, at the second and third interviews, respondents reported that their feelings of happiness were significantly more intense than their feelings of sadness.

Subsequent studies have corroborated that positive emotions are surprisingly prevalent during bereavement. For example, when caregivers of men who died of AIDS were asked to talk about their experiences, about $80 \%$ evidenced positive emotions during the conversation, whereas only $61 \%$ conveyed negative emotions (Folkman, 1997a, 2001; Folkman \& Moskowitz, 2000; Stein, Folkman, Trabasso, \& Christopher-Richards, 1997). Except for just before and just after the death, caregivers' reports regarding positive states of mind were as high as community samples (Folkman, 1997a). A recent study examining positive affect scores of caregivers from 8 months pre-loss to 8 months post-loss demonstrated the presence of positive emotions even within a few weeks before and after the death (Bonanno, Moskowitz, et al., 2005). Comparable findings have been obtained from a study that went beyond self-report data. At 6 months post-loss, Bonanno and Keltner (1997) coded facial expressions of conjugally bereaved respondents while they were talking about their relationship with the deceased. Videotapes of the interviews were then coded for the presence of genuine or "Duchenne" laughs or smiles, which involve movements in the muscles around the eyes. Positive emotion was exhibited by the majority of participants. Moreover, the presence of positive affect was associated with reduced grief at 14 and 25 months post-loss. Those who exhibited Duchenne laughs or smiles also evoked more favorable responses in observers (Keltner $\&$ Bonanno, 1997). In addition to rating them more positively overall, observers rated those who engaged in laughs and smiles as healthier, better adjusted, less frustrating, and more amusing. These findings suggest that one way positive emotions may facilitate coping with loss is by eliciting positive responses from those in the social environment.

\section{Revised Stress and Coping Model}

Drawing on her research on caregivers of men who died of AIDS, Folkman (1997b) concluded that it is important to learn more about how positive psychological states are generated and maintained during a major loss, as well as how they help to sustain coping efforts. In her revision of Lazarus and Folkman's (1984) model of the coping process, Folkman (1997b, 2001) has proposed that when people are distressed as a result of a loss event, they can generate positive emotions by infusing ordinary events with positive meaning. This observation came about in an interesting way. In her study of caregiving partners of men with AIDS, Folkman (1997a) had initially focused exclusively on stressful aspects of the caregiving situation. Respondents were questioned about these every 2 months. Shortly after the study began, several participants "reported that we were missing an important part of their experience by asking only about stressful events; they said we needed to ask about positive events as well if we were to understand how they coped with the stress of caregiving" (p. 1215). Consequently, Folkman added a question in which respondents were asked to describe "something you did, or something that happened to you, that made you feel good and that was meaningful to you and helped you get through the day" (p. 1215). Such events were reported by $99.5 \%$ of the respondents. Events focused on many different aspects of daily life, such as enjoying a good meal, receiving appreciation for something done for one's partner, or going to the movies with friends. Folkman has hypothesized that events of this sort generate positive emotion by helping people feel connected and cared about, by providing a sense of achievement and selfesteem, and by providing a respite or distraction from the stress of caregiving. She has suggested that 
the coping processes that generate positive emotions, and the positive emotions themselves, are likely to help sustain coping efforts in dealing with a stressful situation. Recent empirical evidence is consistent with this prediction. Positive affect not only is quite prevalent at times of adversity but also appears to ameliorate bereavement-related distress (Bonanno, Moskowitz, et al., 2005; Moskowitz et al., 2003). For example, in a recent study on the role of daily positive emotions during bereavement, Ong, Bergeman, and Bisconti (2004) found that the stress-depression correlation was significantly reduced on days in which more positive emotion was experienced.

\section{Broaden-and-Build Theory of Positive Emotions}

Another theory that has important implications for understanding the role that positive emotions may play in coping with loss is Fredrickson's broadenand-build theory of positive emotions (Fredrickson, 1998, 2001; Fredrickson et al., 2003). Fredrickson has maintained that positive emotions can broaden people's attention, thinking, and behavioral repertoire, bringing about an increase in flexibility, creativity, and efficiency and thereby improving their ways of coping with stress. She suggests that over time, this helps people to accumulate important resources, including physical resources (e.g., health), social resources (e.g., friendships), intellectual resources (e.g., expert knowledge), and psychological resources (e.g., optimism). In brief, her work suggests that efforts to cultivate positive emotions in the aftermath of a stressful life experience will pay off in the short run, by improving the person's subjective experience, undoing physiological arousal, and enhancing coping, and in the long term by building enduring resources.

\section{Future Directions}

In subsequent work, it will be important to learn more about how people cultivate and maintain positive emotions in the midst of coping with a major loss. Are there particular strategies that people use to generate and maintain such emotions during a crisis? Are those with certain personality characteristics or belief systems (e.g., those with particular spiritual beliefs) more likely than others to experience positive emotions in the context of adversity? We also need to know more about the impact of positive emotions on adaptation to a major life event such as bereavement. Specific hypotheses could be derived from the Frederickson model, addressing the mechanisms through which positive emotions are thought to improve coping with stress. For example, one could assess whether those who experience positive emotions following a loss indeed show higher flexibility, creativity, and efficiency in terms of their thinking and coping behavior, and determine whether this buffers the negative impact of the loss on people's adjustment. As Folkman (1997b) has pointed out, it may also be the case that positive psychological states must reach a certain level of intensity or duration in order to sustain coping with loss. Future work in this direction is particularly important because strategies that help generate positive emotions in the face of loss are a concrete tool that can be taught as part of an intervention (cf. Fredrickson, 2001). It will also be important to learn more about difficulties the bereaved may encounter in experiencing or expressing positive emotions following a loss. For example, some people may feel guilty if they enjoy something because their loved one is "missing out" on enjoyable experiences. Experiencing or expressing positive emotions may also make people feel that they are being disloyal toward their loved one.

\section{The Importance of Working Through the Loss}

\section{Description}

Among researchers as well as practitioners in the field of grief and loss, it has been commonly assumed that to adjust successfully to the death of a loved one, a person must "work through" the thoughts, memories, and emotions associated with the loss. The term grief work was originally coined by Freud (1917/1957), who maintained that "working through" our grief is critically important-a process we neglect at our peril. Although there is some debate about what it means to "work through" a loss, most grief theorists assert that it involves an active, ongoing effort to come to terms with the death. Implicit in our understanding of grief work is that it is not possible to resolve a loss without it. As Rando (1984) has stated, "For the griever who has not attended to his grief, the pain is as acute and fresh ten years later as it was the day after" (p. 114). Attempts to deny the implications of the loss, or block feelings or thoughts about it, are generally regarded as unproductive. As noted earlier, this view of the 
grieving process has constituted the dominant perspective on bereavement for the past half century (Bonanno, 2001). It is only within the past several years that investigators have begun to question these ideas (see, e.g., Bonanno \& Kaltman, 1999; Stroebe, 1992-1993; Wortman \& Silver, 1989, 2001).

However, an examination of the most influential books on grief therapy suggests that clinicians still regard "working through" as a cornerstone of good treatment (see, e.g., Rando, 1993; Worden, 2002). Consequently, the treatment goal for clinicians typically involves facilitating the expression of feelings and thoughts surrounding the loss (see Bonanno, 2001, for a more detailed discussion). Clinicians have also emphasized the importance of expressing negative feelings that are directed toward the deceased, such as anger or hostility (see, e.g., Lazare, 1989; Raphael, 1983). In fact, practitioners have frequently argued against the use of sedative drugs in the early phases of mourning because they may interfere with the process of "working through" the loss (see Jacobs, 1993, for a more detailed discussion). As Jacobs (1993) has indicated, such attitudes are prevalent among practicing clinicians despite the fact that there is "little or no evidence for the idea" (p. 254).

\section{Evidence on "Working Through"}

Over the past decade, several studies relevant to the construct of "working through" have appeared in the literature. These studies have assessed such constructs as confronting thoughts and reminders of the loss versus avoiding reminders and using distraction (e.g., Bonanno et al., 1995; Bonanno \& Field, 2001; M. Stroebe \& Stroebe, 1991); thinking about one's relationship with the loved one (e.g., Nolen-Hoeksema et al., 1997); verbally expressing or disclosing feelings of grief or distress (e.g., Lepore, Silver, Wortman, \& Wayment, 1996); exhibiting negative facial expressions (e.g., Bonanno \& Keltner, 1997; Keltner \& Bonanno, 1997); or expressing one's feelings through writing about the loss (Lepore \& Smyth, 2002; Pennebaker, Zech, \& Rime, 2001; Smyth \& Greenberg, 2000). These studies have provided limited support for the notion that "working through" is important for adjustment to the death of a loved one. Some have not found any support for the grief work hypothesis, some have found support on only a few dependent measures, and some have reported findings that directly contradict this hypothesis.

\section{Confronting Versus Avoiding Loss}

In one of the earliest studies on grief work, M. Stroebe and Stroebe (1991) assessed five kinds of behaviors associated with confronting the loss of one's spouse or with avoidance (e.g., disclosed one's feelings to others; avoided reminders), at 4 to 7 months, 14 months, and 2 years post-loss. At the final time point, there were no differences between widows who had showed evidence for confronting their loss at either of the first two time points and those who did not. However, for two of the five measures (those assessing distraction and suppression), widowers who confronted their grief showed lower subsequent depression. Overall, these results provide limited support for the grief work hypothesis, leading M. Stroebe and Stroebe (1991) to conclude that the statement "'Everyone needs to do grief work' is an oversimplification" (p. 481).

In another study comparing those who used avoidant versus more confrontative coping styles (Bonanno et al., 1995; Bonanno \& Field, 2001), respondents who had lost a spouse were asked to talk about their relationship to the deceased, and their feelings about the loss, at the 6-month point following their loss. Physiological data assessing cardiovascular reactivity were also collected. Respondents who evidenced emotional avoidance (i.e., little emotion relative to their physiological reactivity) showed low levels of interviewer-rated grief throughout the 2-year study. Among respondents who initially showed emotional avoidance, there was no evidence of delayed grief. Although respondents with an avoidant style did show higher levels of somatic complaints at 6 months post-loss, these symptoms did not persist beyond the 6-month assessment and were not related to medical visits.

In a study of gay men who lost a partner to AIDS, Nolen-Hoeksema and colleagues (1997) examined the impact of thinking about one's relationship with the partner versus avoiding such thoughts. Those who had thought about their life without their partner, and how they had changed as a result of the loss, showed more positive morale shortly after the death, but showed more depression over the 12 months following the loss.

Taken together, these results suggest that many respondents do not make an active, ongoing effort to confront the loss but nonetheless evidence good adjustment following bereavement. Apparently, focusing attention away from one's emotional distress 
can be an effective means of coping with the loss of a loved one.

\section{Talking About Negative Feelings}

A study by Bonanno and Keltner (1997) casts doubt on the value of expressing negative feelings. These investigators assessed the expression of negative emotion in two ways: through self-report and through facial expressions. An advantage of studying facial expressions is that they can be assessed independently of self-report and even without participant awareness. Those who expressed negative feelings or manifested negative facial expressions while talking about the decreased 6 months postloss showed higher interviewer-rated grief 14 months post-loss. This was particularly the case for facial expressions of anger, the emotion most consistently believed by grief work theorists to require expression (Belitsky \& Jacobs, 1986).

As Bonanno (2001) has indicated, it was not clear from these studies whether the expression of negative emotions actually influenced subsequent grief, or whether individuals in a more acute state of grief merely tended to express more negative emotions-in other words, the expression of negative affect may have simply been a by-product of grief. To address this concern, Bonanno (2001) reanalyzed the facial data controlling for the initial level of grief and distress, which enabled him to isolate the extent to which expressing negative emotion was related to subsequent grief. Even under these stringent conditions, facial expressions of negative emotion were still related to increased grief at 14 months post-loss. These studies by Bonanno and his associates suggest that minimizing the expression of negative emotion results in reduced grief over time, which is just the opposite of what the grief work hypothesis would predict.

\section{Writing About Negative Feelings}

One problem in interpreting the previously described findings by Bonanno has been identified by Pennebaker et al. (2001). These investigators have pointed out that the best predictor of future distress is current distress, and that it is important to differentiate among those studies where distress is a reflection of grief from those studies where respondents participate in an intervention that allows them to work through their grief.

To provide a more convincing test of the value of expression, Pennebaker and his associates devel- oped a writing intervention that provides the opportunity for people to engage in emotional expression following trauma or loss. Participants are asked to write essays expressing their deepest thoughts and feelings about the most traumatic event they can remember. Control participants are asked to write about innocuous topics, such as their plans for the day. Typically, participants write for 20 to 30 minutes on several consecutive days (see, e.g., Pennebaker $\&$ Beall, 1986). When given these instructions, people are indeed willing to write about experiences that are very traumatic and upsetting. According to Pennebaker et al. (2001), "Deaths, abuse incidents, and tragic failures are common themes" (p. 530).

It has been shown that writing has a positive impact on such health outcomes such as health center visits and immunologic status. Although the literature on the impact of writing on mood and psychological well-being is somewhat mixed (see Pennebaker et al., 2001, for a review), a meta-analysis suggested that overall, mood and psychological well-being being improve following writing. The results also suggested that writing can affect health outcomes as well as behavioral changes, such as an improvement in grades, or the ability to get a new job after being laid off. Hence, the results illustrate that the impact of writing is not restricted to any one outcome. Interestingly, writing did not seem to confer benefits on health behaviors. Smyth's (1998) study suggested that the effects produced by the writing task are substantial, and are similar in magnitude to other psychological interventions.

Do these writing effects apply to individuals who have lost a loved one? Pennebaker et al. (2001) have estimated that across the studies conducted in his lab, approximately $20 \%$ of participants write about the death of a close friend or family member. According to these investigators, people who write about death benefit as much as people who write about other topics. However, studies focusing on the value of emotional expression among the bereaved have produced inconclusive findings (see M. Stroebe, Stroebe, Schut, Zech, \& van den Bout, 2002, for a review). For example, Segal, Bogaards, Becker, and Chatman (1999) conducted a study with elderly people who had lost a spouse an average of 16 months previously. Respondents were instructed to talk into a tape recorder about the loss and to express their deepest feelings. When compared with a delayed treatment control condition, 
those who expressed their feelings showed a slight but nonsignificant improvement in hopelessness. No significant effects emerged on other measures of distress such as depression and intrusion/avoidance.

Two studies by Range and her associates (Kovac \& Range, 2000; Range, Kovac, \& Marion, 2000) also fail to support the value of written emotional expression among the bereaved. In the first study (Range et al., 2000), undergraduates who had experienced the loss of a friend or family member as a result of an accident or a homicide were asked to write about their deepest thoughts and feelings surrounding the death. A control group was asked to write about a trivial issue. The results revealed that both groups showed improvements in symptoms of depression, anxiety, and grief during the course of the study. There was no indication of greater improvement among respondents who were assigned to express their feelings. There were also no differences among the two groups in doctor visits. In the second study, people who had lost a loved one to suicide were invited to express their deepest feelings or to write about a trivial issue. The study included many dependent measures such as intrusion/avoidance, doctors' visits, and grief. On the majority of measures, there were no differences between the groups. Similar results were also obtained in an intervention study by Bower, Kemeny, Taylor, and Fahey (2003). Women who had lost a close relative to breast cancer were assigned to write about the death or about neutral topics. Writing did not appear to facilitate adaptation to the loss.

Stroebe et al. (2002) conducted two exceptionally well-designed studies to determine whether expression of emotions facilitates recovery among the bereaved. In the first study, the authors focused on disclosures of emotion made by the bereaved in everyday life. A large sample of people who had lost a spouse were asked to complete a questionnaire designed to assess disclosure of emotion to others at four points over a 2 -year period. The results provided no evidence that disclosure facilitated adjustment to loss. In the second study, people who lost a spouse from 4 to 8 months previously were randomly assigned to one of three writing conditions or to a control no-writing condition. Participants in the first writing condition were instructed to focus on their emotions. Those in the second condition were told to focus on problems and difficulties they have to deal with as a result of the death. The final group was asked to focus on both their feelings and problems. The results of this study provided no evidence whatsoever for a general beneficial effect of emotional expression. None of the experimental groups was better off than control respondents on any measures.

To determine whether the emotional expression of grief may be beneficial under specific conditions, M. Stroebe et al. (2002) further examined whether writing effects were a function of the type of loss. When they compared bereaved participants who expected the loss with those who had encountered a sudden, unexpected loss, there was no indication that emotional expression through writing was more beneficial for the latter group. They also investigated whether the expression of emotions may work only among people who have not yet had much opportunity to disclose their feelings. However, they found no evidence to suggest that those who had rarely disclosed their feelings in the past benefited more from the writing intervention than those who had disclosed their feelings more frequently. In fact, these investigators found that it was low disclosers who were less likely to suffer from intrusive thoughts, and who had fewer doctor visits, than high disclosures.

\section{Traditional, Conditional, or Modified Grief Work Hypothesis}

In a study on grief processing and deliberate grief avoidance among bereaved spouses and parents in the United States and the People's Republic of China, Bonanno, Papa, Lalande, Zhang, and Noll (2005) tested different versions of the grief work hypothesis, using a comprehensive measure of grief processing that included thinking and talking about the deceased, having positive memories, expressing feelings, and searching for meaning. These authors also used a measure of grief avoidance that included avoidance of thinking, talking, and expressing feelings about the deceased. This study addressed (a) the traditional hypothesis that grief processing was a necessary step toward positive adjustment, and that the absence of grief processing reflects avoidance or denial; (b) the conditional hypothesis that grief work may be beneficial for those with severe grief; and (c) another modified hypothesis that grief work was more akin to rumination, with the prediction that those who scored high on grief processing initially would continue to score high on this measure and show poorer adjustment at the 18-month follow-up than those who did not score high on initial grief processing. 
Support was found for the third but not for the first two hypotheses. Moreover, grief processing and grief avoidance were independent predictors of outcome in both cultures, which indicates that they can coexist rather than represent opposite ends of one dimension. Grief processing and avoidance each predicted poorer adjustment for U.S. participants, even for those who had shown more severe grief initially. The authors interpreted this as contradictory to both the traditional and the conditional grief work hypothesis but as consistent with the grief work as rumination hypothesis. Grief processing and avoidance did not emerge as significant predictors of outcome among the Chinese participants, which may have reflected cultural differences in terms of mourning rituals and practices. Overall, the authors concluded that these findings cast doubt on the usefulness of grief processing and argued that it may be inadvisable to encourage the bereaved to focus on processing the loss.

When reviewing the different studies that have tested the grief work hypothesis, it is important to keep in mind how grief work was conceptualized in each study, and how this may have affected the findings. For example, it is possible that Bonanno, Papa, et al. (2005) failed to find positive effects of grief processing because their grief processing measure included the expression of feelings, which, as discussed previously, has been found to predict worse outcome in some studies, and searching for meaning, which may be regarded as reflective of ruminative thinking. There is evidence that rumination, if defined as engaging in thoughts and behaviors that maintain one's focus on negative emotions (Nolen-Hoeksema, 1991), heightens distress, interferes with problem solving, and may drive away potential supporters.

\section{Future Directions}

In future work, it will be important to include separate assessments of constructs pertaining to working through, such as thinking about the loss, talking about what has happened, crying, or searching for meaning. This would help to clarify how these constructs are related to one another and to identify the role played by each in the process of recovery. When comparing findings from different studies on this issue, and in particular when drawing conclusions about adaptiveness, it is extremely important to be clear about what kind of grief processing is talked about in each specific case. This also leads to the more general question regarding what kind of grief processing may be beneficial for whom, and under which circumstances. For example, one reason the literature on "working through" may be so inconsistent is because some studies may have included people who did not need to "work through" what happened, some who may have been reluctant to engage fully in the process, and some who were made worse by being required to confront the trauma. Those who may have difficulty expressing their emotions seem to benefit the most from interventions such as writing about their experience (Lumley, Tojeck, \& Macklem, 2002; Norman, Lumley, Dooley, \& Diamond, in press). Furthermore, it is possible that "working through" may be more beneficial for certain kinds of events, such as those that are particularly traumatic and/or likely to shatter the survivors' views of the world. We also need to know more about the conditions under which emotional expression reduces the bereaved person's distress, helps him or her to gain insight or cognitively structure what has happened, and helps to elicit support and encouragement from others. Hopefully, subsequent research will assist us in specifying the conditions under which "working through" one's loss is more or less likely to be beneficial, and if it is indicated, how this grief processing needs to be done in order to truly facilitate recovery and adjustment.

\section{Breaking Down Attachments}

\section{Description}

According to the traditional view on grief, espoused by Freud (1917/1957) and other psychoanalytic writers (e.g., Volkan, 1971), it is necessary to disengage from the deceased in order to get on with life. These writers believed that for grief work to be completed, the bereaved person must withdraw energy from the deceased and thus free him- or herself from attachment to an unavailable person. This view remained influential for many years, with its advocates maintaining that if attachments are not broken down, the bereaved will be unable to invest their energy in new relationships or activities. It is generally believed that bereaved people accomplish this task by carefully reviewing thoughts and memories of the deceased, as well as both positive and negative aspects of the relationship (see, e.g., Rando, 1993; Raphael, 1983). Clinicians have traditionally maintained that the failure to break down 
bonds with the deceased is indicative of a need for treatment. In fact, relinquishing the tie to the deceased has been a major goal of grief therapy (see, e.g., Raphael \& Nunn, 1988; Sanders, 1989).

During the past decade, this view has been called into question (see Stroebe \& Schut, 2005, for a review). Indeed, an increasing number of researchers now believe that it is normal to maintain a continuing connection to the deceased, and that such a connection may actually promote good adjustment to the loss (Attig, 1996; Klass, Silverman, \& Nickman, 1996; Neimeyer, 1998; Shmotkin, 1999). Others have maintained that it is time to move beyond the dichotomy of disengagement versus continuing connection (Boerner \& Heckhausen; 2003; Russac, Steighner, \& Canto, 2002). For example, Boerner and Heckhausen (2003) conceptualized adaptive bereavement as a process of transforming mental ties to the deceased that involves features of both disengagement and continuing connection. They further proposed that this process of transforming the relationship occurs by substituting mental representations of the deceased for the lost relationship. Such mental representations may simply reflect experiences that are retrieved from memory (e.g., remembering what the deceased said in a particular situation). Others may be newly constructed by adding new aspects to one's preexisting image (e.g., imagining what the deceased would say). Boerner and Heckhausen (2003) also noted that different ways of transforming the relationship may be more or less adaptive for a particular person. Stroebe and Schut (2005) extended this view by arguing that certain types of continuing bonds, as well as certain types of relinquishing bonds, can be helpful or harmful. Their notion of relinquishing ties, however, is one of "relocating" rather than "forgetting" the deceased, reflecting the idea of transforming the nature of the relationship to symbolic, internalized, imagined levels of relatedness (Boerner \& Heckhausen, 2003; Shuchter \& Zisook, 1993; Stroebe \& Schut, 2005).

Historically, one of the first theorists to question the importance of breaking down attachments was Bowlby (1980). In his later writings, Bowlby maintained that continuing attachments to the deceased, such as sensing his or her presence or talking with him or her, can provide an important sense of continuity and facilitate adjustment to the loss. A similar view has been expressed by Hagman $(1995,2001)$, who argued that there had been too much emphasis on relinquishment of the bond with the deceased. In fact, Hagman indicated that in some cases, it is more adaptive to restructure one's memories of the deceased so as to allow a continuing connection. In their influential book, Continuing Bonds, Klass et al.(1996) also emphasized the potential value of maintaining a connection with the deceased. These investigators noted that their training led them to expect grief resolution to be accompanied by breaking down attachments to the deceased. However, this is not what they found in their research or in their clinical work. Instead, their work indicated that most people experienced a continuing connection with the deceased and that these connections "provided solace, comfort, and support, and eased the transition from the past to the future" (p. xvii).

Just as it was previously argued that breaking the bond between the bereaved and deceased should be an important goal of therapy, many clinicians now argue that such bonds should be facilitated as part of bereavement counseling. Silverman and Nickman (1996) concluded that the tie between the bereaved and the deceased loved one should be viewed as a strengthening resource, and that it should be explicitly encouraged in bereavement interventions. Along similar lines, Fleming and Robinson (1991) have argued that it is important for the bereaved to confront such questions as what he or she has learned from the deceased, and how he or she has changed as a result of the relationship with the deceased. Neimeyer $(2000,2001)$ has proposed a number of innovative methods for developing an ongoing connection with the deceased, such as writing a biographical sketch of the deceased or writing letters to the deceased along with imaginary answers, which are to be written by the bereaved from the deceased person's perspective. Other investigators have provided specific suggestions about how to learn more about the deceased and his or her possible influence on one's life. For example, Attig (2000) has indicated that it can be helpful to explore records such as letters or diaries, as well as sharing memories with others who knew the deceased. He has suggested that the bereaved can benefit considerably by talking with people who may have a different perspective on the deceased. For example, a wife might seek out opportunities to talk with her deceased husband's coworkers, or parents may make an effort to talk with the friends of their deceased adolescent son. 


\section{Evidence for Prevalence and Types of Continuing Connections}

Does empirical evidence support the view that continuing attachments to the deceased are common, and that they facilitate good adjustment? Since the 1970s, studies have appeared in the literature suggesting that many forms of attachment to the deceased are common (see, e.g., Glick, Weiss, \& Parkes, 1974; Parkes \& Weiss, 1983; Rees, 1971). The most frequently studied forms of attachment include sensing the presence of the deceased, seeing the deceased as protecting or watching over oneself, and talking to the deceased (see Klass \& Walter, 2001, for a review). For example, Zisook and Shuchter (1993) found that 13 months after their spouse's death, $63 \%$ of the respondents indicated that they feel their spouse is with them at times, $47 \%$ indicated that he or she is watching out for them, and 34\% reported that they talk with their spouse regularly. Similar results have been reported by Stroebe and Stroebe (1991), who found that 2 years following the death of a spouse, a third of the bereaved still sensed the presence of the deceased. Results suggesting a continuing connection between the deceased and the bereaved have also been reported by Bonanno, Mihalecz, and LeJeune (1999) in a study of the emotional themes that emerge during bereavement. These investigators have reported that 6 months after the loss, more than $80 \%$ of the bereaved described emotional themes indicative of an enduring positive bond. Similar findings were obtained by Richards, Acree, and Folkman (1999) in their study of bereavement among caregivers of men who died of AIDS. These investigators reported that 3 to 4 years post-loss, $70 \%$ of the bereaved caregivers reported an ongoing inner relationship with their deceased partner. Continuing ties with the deceased took many forms: some deceased partners were thought to serve as guides, some were believed to be present at times, and some "talked with" the bereaved partner. A sense of closeness with the deceased persisted even though most of the men had made life changes (e.g., changing jobs or living situations). As Richards et al. (1999) have indicated, "The continued relationship to the deceased did not appear to be an aspect of clinging to the past but, rather, a part of a reorganized present where the deceased assumed a new position in the living partner's world scheme" (pp. 122-123).
Data from the Harvard Child Bereavement Study (Silverman \& Worden, 1992) indicate that it is common for children to maintain a connection with deceased parents. Silverman and Nickman (1996) reported that 4 months after losing a parent, $74 \%$ of the children had located their parent in heaven, and most viewed the parent as watching out for them. Moreover, nearly $60 \%$ of the children reported that they talked with the deceased parent, and 43\% indicated that they received an answer. A year following the loss, these attachment behaviors were still very prevalent, with nearly $40 \%$ of the children indicating that they talked with their deceased parent.

There has also been interest in connections in which the deceased loved one serves as a moral compass or guide (see, e.g., Klass \& Walter, 2001; Marwit \& Klass, 1996). Although this form of continuing bond has received less study than those mentioned earlier, Glick, Weiss, and Parkes (1974) found that at 1 year following the loss, $69 \%$ of those who lost a spouse expressed agreement with the statement that they try to behave as the deceased would want them to. Similarly, Stroebe and Stroebe (1991) found that at 2 years following the death of their spouse, half of the respondents indicated that they consulted the bereaved when they had to make a decision. Several similar kinds of attachment behavior have been described in the literature, including relying on the deceased as a role model, incorporating virtues of the deceased into one's character, working to further the deceased's interests or values, and reflecting on the deceased person's life and/or death to clarify current values or value conflicts (Marwit \& Klass, 1996; Normand, Silverman, \& Nickman, 1996).

Relatedly, Field, Gal-Oz, and Bonanno (2003) assessed a wide variety of attachment behaviors. They included such items as attempting to carry out the deceased's wishes, having inner conversations with the deceased, taking on the spouse's values or interests, using the spouse as a guide in making decisions, reminiscing with others about the spouse, experiencing the spouse as continuing to live through oneself, having fond memories of the spouse, and seeing the spouse as a loving presence in one's life. The results indicated that most of these types of connection were quite prominent even at 5 years after the loss. On average, participants endorsed these items in the range of "moderately true." Items that received the highest scores 
included keeping things that belonged to one's spouse, enjoying reminiscing with others about one's spouse, seeing the spouse as a loving presence in one's life, expressing awareness of the positive influence of one's spouse on who one is today, and having fond memories of one's spouse. Items endorsed less frequently at 5 years post-loss included seeking out things that remind one of his or her spouse, awareness of taking on one's spouse's values or interests, and having conversations with one's spouse.

\section{Continuing Connections and Adaptation}

Although many studies have examined the prevalence of continuing connections to the deceased among the bereaved, only a few have examined the relationship between such connections and adaptation to the loss. These studies have yielded inconclusive evidence. In studies assessing the frequency of sensing the presence of the deceased or talking with him or her, the majority of respondents experience these encounters as comforting (Klass \& Walter, 2001). Silverman and Nickman (1996) have also noted that the ties that children developed with their deceased parents were apparently beneficial. Many children made spontaneous comments such as "It feels good to think about him." In fact, when the children were asked what they would advise another bereaved child to do, they gave answers such as "Just think of them as often as you can." However, as other investigators have noted (cf. Fraley \& Shaver, 1999), a significant minority of survivors report that ongoing connections are not always comforting. For example, nearly $60 \%$ of the children in the study by Silverman and Nickman (1996) indicated that they were "scared" by the idea that their parents could watch them from heaven. In fact, some children regarded their deceased parent as a ghost whose presence was frightening and unpredictable (Normand, Silverman, \& Nickman, 1996). In a follow-up analysis of these data, Silverman, Baker, Cait, and Boerner (2003) found that many of the children who showed emotional and behavioral problems after the loss had a continuing bond with the deceased that was primarily negative. These "high-risk" children carried troubling legacies related to their deceased parent's health, personality, or role in the family. Health-related legacies, for example, reflected children's fear that they will die from the same condition or disease that killed their parent. Role-related legacies reflected children's sense that they needed to assume the role in the family that was once filled by the parent, creating a burden that was clearly too heavy for these children.

Datson and Marwit (1997) found that 60\% of those who had lost a loved one within the previous 4 years reported sensing the presence of their deceased loved one at some point, and the vast majority (86\%) regarded the experience as comforting. However, those who reported that they had sensed the presence of their loved one scored higher in neuroticism than those who did not. These findings suggest that sensing the presence of the deceased loved one may be more an indication of greater distress than a sign of good adjustment.

In a study by Field, Nichols, Holen, and Horowitz (1999), interviewers rated the extent to which bereaved individuals manifested four different kinds of attachment behaviors 6 months after the loss. Those who tended to maintain the deceased person's possessions as they were when he or she was alive, or who tended to make excessive use of the deceased's possessions for comfort, exhibited more severe grief symptoms over the course of the 25-month study. These respondents also showed less of a decrease in grief symptoms over time. Attachment strategies that involved sensing the deceased spouse's presence, or seeking comfort through memories of their loved one, were not related to the intensity of grief. These findings suggest that whether continuing bonds are adaptive or maladaptive may depend on the form that the connection takes.

To address this question, Field et al. (2003) conducted a follow-up study on this same sample, in which they assessed a wider variety of attachment behaviors at 5 years post-loss (see earlier discussion). Results showed that each of the continuing bond items, as well as a composite score based on all of the items that were assessed, was associated with more severe grief. There was a strong positive correlation between continuing bonds assessed 5 years after the death and grief assessed at the same time point. The relationship between continuing bonds and other forms of well-being was much weaker, suggesting that the relationship between continuing bonds and adjustment is largely restricted to grief-restricted measures.

In another study, Field and Friedrichs (2004) examined the use of attachment behaviors as a way of coping with the death of a husband. Fifteen early-bereaved widows (4 months post-loss) and 
15 later-bereaved widows (more than 2 years) completed continuing bond and mood measures four times each day for 14 consecutive days. Greater use of continuing bond coping was related to more positive mood among the later- but not the earlybereaved, and more negative mood in both groups. Furthermore, in time-lagged analyses, greater use of continuing bond coping was predictive of a shift toward more negative mood among early-bereaved but not among later-bereaved widows. These findings suggest that continuing bond coping may be less effective in mood regulation earlier than later on after the death. As the authors noted, however, neither this nor the prior two studies allowed for a investigation of the direction of causality between continuing bonds and grief symptoms. Hence, it is not clear whether continuing bonds are simply correlates of bereavement-related distress or whether the formation of such bonds in fact plays a causal role in impending adjustment to bereavement. Nonetheless, when considered together, these studies raise questions about whether continuing bonds should be regarded as exclusively adaptive.

In summary, our belief in the value of continuing attachments between the bereaved and the deceased has shifted markedly over the past few decades. Initially, it was believed that it was essential to break down ties to the deceased. At present, such ties are widely regarded as normal and generally beneficial. Because so few studies have examined the role such ties may play in adjustment to loss, there is virtually no evidence to support this current view. In fact, the few studies that have explored the matter suggest that it would be a mistake to regard continuing bonds as uniformly adaptive.

\section{Future Directions}

In future work, it will be important to learn more about whether certain kinds of continuing bonds may facilitate good adjustment while others do not. Some types of behaviors may in fact reflect the presence of continuing bonds, whereas others may signal the presence of other psychological processes. Maintaining the deceased person's possessions as they were, for example, may reflect failure to accept the loss rather than a continuing attachment to the deceased. Results of the studies by Field et al. (1999, 2003) also suggest that whether continuing bonds are adaptive may depend on how much time has elapsed since the death. At this point, we do not know whether those who make the best adjust- ments to a loss experience continuing bonds for several years into the future, or whether these bonds gradually fade over time as the bereaved become involved in other relationships and activities. By examining a large and representative class of continuing bonds from shortly after the loss through the next several years, it should be possible to address critical questions about the possible causal role continuing bonds may play in facilitating adjustment. Such questions could also be addressed through experimental studies in which respondents are randomly assigned to participate in exercises believed to promote continuing bonds, such as discussions about what the deceased loved one has meant to them.

Even if continuing bonds are generally found to facilitate adjustment, there may be conditions under which this is not the case. Negative legacies from past relationships can be related to aspects of the deceased's life (e.g., health aspects, or burdensome roles that were once filled by the deceased), or to aspects of the relationship with the deceased (e.g., if the relationship was abusive or destructive in other ways). If the bereaved is left with such a negative legacy, what kind of a connection to the deceased, if any, should the bereaved attempt to develop? In some cases, perhaps reviewing the relationship, and the negative legacy that is attached to this relationship, can help the bereaved to attain important self-knowledge. However, it may be this self-knowledge (e.g., I deserved to be with someone who treated me better) rather than a positive tie with the deceased that is helpful to the person under such conditions.

In the process of clarifying the relationship between various continuing bonds and adjustment, it would be valuable to have a greater understanding about how particular sorts of connections are experienced and perceived by the bereaved. For example, although it is common for the bereaved to talk with the deceased and to report that this is comforting, little is known about what transpires in such conversations or what psychological needs they may fulfill. It will also be important to determine whether there are circumstances that might impede or facilitate the development of continuing bonds that facilitate adjustment. For example, the opportunity to talk with others who knew and valued the deceased may help to facilitate the development of such bonds. However, it may be more difficult for the bereaved to develop such bonds 
following a loss that cannot be acknowledged or shared, or after a sudden, traumatic loss, where there is no opportunity to prepare for the loss or to say good-bye (Boerner \& Heckhausen, 2003).

\section{Expectations About Recovery}

\section{Description}

Traditionally, it has been believed that once people have completed the process of "working through" the loss and "relinquishing their ties to the deceased," they will reach a state of recovery. Most prior work has conceptualized recovery in terms of a return to prebereavement or baseline levels of psychological distress. As Weiss (1993) has emphasized, however, it is important to examine a broader set of indicators when trying to determine whether a person has recovered from a loss. These include freedom from intrusive or disturbing thoughts and the ability to encounter reminders without intense pain; the ability to give energy to everyday life; the ability to experience pleasure when desirable, hoped-for or enriching events occur; hopefulness about the future and being able to make and carry out future plans; and the ability to function well in social roles such as spouse, parent, and member of the community.

In the past, bereavement has been viewed as a time-limited process, with people resuming "normal life" once they reach the end point (Malkinson, 2001). It was assumed that in most cases, grief work would be completed in approximately 12 months (Malkinson, 2001; Wortman \& Silver, 2001). Those who fail to recover after an "appropriate" amount of time were often viewed as displaying "chronic" grief (see, e.g., Jacobs, 1993), a pattern of grieving that has been regarded as an indication of "pathological mourning" (Middleton et al., 1993). Over the past decade, however, this view of the recovery process has begun to change. Malkinson (2001) has noted that at this point, the 12-month time period is viewed as "mythological" and that there is wide recognition that the process can take far longer.

Moreover, recovery is no longer viewed as a process with a discrete end point. As widows and widowers sometimes express it, "You don't get over it, you get used to it" (Weiss, 1993, p. 277). Several investigators have pointed out that terms like resolution and recovery are becoming unpopular, and that they are not applicable to most losses because they imply a once-and-for-all closure that does not occur (see, e.g., Rando, 1993; Klass, Silverman, \& Nickman, 1996; Stroebe, Hansson, et al., 2001; Weiss, 1993). Similarly, there is a growing consensus that bereaved individuals may never return to their pre-loss state. Weiss (1993) has argued that a major loss will almost invariably produce changes in a person's character. Miller and Omarzu (1998) have suggested that returning to one's preloss state may not be an optimal goal. As Malkinson (2001) has expressed it, recovery can be "a lifelong process of struggling to find the balance between what was and what is" (p. 675).

\section{Evidence for Chronicity}

Empirical evidence suggests that while most bereaved individuals do not seem to experience intense distress for extended periods of time (see the earlier section on the expectation of intense distress), a significant minority of people experience long-term difficulties. This was found in the six longitudinal studies mentioned previously that included two postloss time points and provided evidence for different patterns of grief. "Chronic" grief, which involved scoring high in distress at both time points, was found among 30\% of participants in the study on the loss of a child from SIDS (Wortman $\&$ Silver, 1987), and anywhere between $8 \%$ and $26 \%$ in studies on conjugal loss (24\% in Bonanno et al., 1995; 13\% in Bournstein et al., 1973; 8\% in Lund et al., 1986; 26\% in Vachon, Rogers, et al., 1982; and 20\% in Zisook \& Shuchter, 1986). It should be noted that the highest percentage for a pattern of consistently high levels of distress following the loss came from the study on death of a child to SIDS (Wortman \& Silver, 1987). Another important consideration is the striking difference among the studies on conjugal loss in the percentage of respondents evidencing chronic grief. This may be related to differences in the age of the respondents, and hence the timeliness of the loss. For example, the study by Lund et al. (1986) focused on elderly bereaved, whereas the study by Vachon, Rogers, et al. (1982) focused on loss of a spouse at midlife.

In our prospective work on conjugal loss (Bonanno et al., 2002), the availability of pre-loss data made it possible to further distinguish a chronic grief pattern, scoring low before the loss and consistently high afterward (16\%), from chronic depression (8\%), which involved scoring high at all preand postloss time points. To further characterize the nature of these patterns, Bonanno et al. (2002) iden- 
tified their pre-loss predictors. Chronic grievers were likely to have had healthy spouses, to rate their marriage positively, and to show high levels of preloss dependency (e.g., agreeing that no one could take the spouse's place). The chronically depressed group was less positive about their marriage than chronic grievers, but as dependent on their spouse. Further analyses examined the context and processing of the loss at 6 and 18 months post-loss (Bonanno et al., 2004). Results suggest that chronic grief stems from an enduring struggle with cognitive and emotional distress related to the loss, whereas chronic depression results more from enduring emotional difficulties that are exacerbated by the loss. For example, at 6 months postloss, chronic grievers were more likely to report current yearning and emotional pangs, and they reported thinking and talking about the deceased more often than did chronically depressed individuals.

Most classic grief theorists (e.g., Jacobs, 1993) discuss the notion of chronic grief but fail to indicate how long it typically takes and whether it abates. To address this issue, we conducted a follow-up analysis investigating whether the chronic grievers and the chronically depressed would remain distressed up to 48 months post-loss (Boerner et al., 2005). Overall, the chronic grief group experienced a more intense and prolonged period of distress than, for example, did the common grief group. Measures of outcome and processing the loss measures, however, indicated a turn toward better adjustment by the 48-month time point, which suggests that this group does not remain chronically distressed as a result of the loss. In contrast, the chronically depressed group clearly demonstrated long-term problems, with little indication of improvement between 18 and 48 months. This group not only showed the poorest adjustment 4 years after the loss but also struggled the most with questions about meaning. These differential findings for the chronic grief and chronic depression group underscore the need to further refine the criteria that are used to identify those who are at risk for long-term problems.

\section{Risk Factors}

Over the past decade, it has become increasingly clear that reactions to loss are highly variable, but that a significant minority shows enduring effects. Consequently, researchers have become interested in identifying factors that may promote or impede successful adjustment to the loss of a loved one. Studying risk factors has the potential to advance bereavement theory by helping to clarify the mechanisms through which loss influences subsequent mental and physical health. Perhaps even more important, knowledge about risk factors can aid in the identification of people who may benefit from bereavement interventions.

Several broad classes of risk factors have been studied in the literature (see Archer, 1999; Jordan $\&$ Neimeyer, 2003; and Stroebe \& Schut, 2001, for reviews). These include demographic factors, such as age, gender, and socioeconomic status; background factors, including whether the respondent has a history of mental health problems or substance abuse, or has experienced prior losses or traumas; factors describing the type and nature of the relationship, such as whether it was a child, spouse, or sibling who was lost and whether the relationship was emotionally close or conflictual; personal and social resources, including personality traits, attachment history, religiosity, and social support; and the context in which the loss occurs, which refers to the circumstances surrounding the death, whether the surviving loved one was involved in caregiving, the type and quality of the death, and the presence of concomitant stressors such as ill health of the surviving loved one. A comprehensive review of these risk factors is beyond the scope of this chapter. However, in this section, we wish to highlight selected areas of research on risk factors that we believe are of emerging interest and importance.

Most of the research on gender differences following the loss of a loved one has focused on the loss of a spouse. There is clear evidence that in comparison to married controls, widowed men are more likely to become depressed and to experience greater mortality than are widowed women (see Stroebe, Stroebe, et al., 2001, and Miller \& Wortman, 2002, for reviews). Interestingly, such deaths are especially likely among younger bereaved men. Major causes of death among bereaved men include alcohol-related illness, accidents and violence, suicide, and chronic ischemic heart disease.

One possible explanation for these gender differences is that men may benefit more from marriage than do women, and may therefore be more adversely affected when the marriage ends. Consistent with this view, several studies have shown that women typically have many more close social relationships than men, who rely primarily on their 
wives for support. In addition, women usually perform more housework and child care than do men. Because men often rely on their wives in these domains, they may find it difficult to handle these matters on their own. Research suggests that while social ties and household responsibilities are related to gender differences following conjugal loss, they account for relatively little variance in the relationship between widowhood and mortality or depression (Miller \& Wortman, 2002).

A second mechanism has been suggested by Umberson (1987, 1992), who has demonstrated that women typically take greater responsibility for their partner's health care, diet, nutrition, and exercise than do men. For example, married women are typically the ones who schedule doctor appointments and regular checkups for themselves and their spouses. They are also more likely to monitor whether their husbands are taking prescribed medications, and to offer reminders if necessary. Married women are also more likely to place constraints on negative health behavior, such as drinking and driving. Umberson concludes that the poor health of men following the death of their spouse is caused in part by the loss of this positive influence on their health behavior.

Several comparative studies of different kinship relationships have shown that the loss of a child results in more intense and prolonged grief and depression than the loss of a spouse, parent, or sibling (see Stroebe \& Schut, 2001, for a review). Available research suggests that mothers are more adversely affected than fathers by the loss of a child (see Archer, 1999, for a more detailed discussion). In most studies focusing on the death of a child, mothers typically report higher levels of grief, psychological distress, preoccupation with the loss, intrusive thoughts, and feelings of guilt than do fathers (see, e.g., Dyregrov et al., 2003).

Virtually all of the studies that have examined how bereavement is affected by the nature of the relationship have focused on the loss of a spouse. Historically, clinical writings on loss have maintained that chronic grief results from conflict in the marital relationship or feelings of ambivalence toward the spouse (see, e.g., Bowlby, 1980; Freud, 1917/1957; Parkes \& Weiss, 1983). However, wellcontrolled studies fail to provide support for this view (Bonanno et al., 2002; Carr et al., 2000). Clinicians have also maintained that excessive dependency on one's spouse is a risk factor for chronic grief (see, e.g., Lopata, 1979; Parkes \& Weiss, 1983). Available evidence suggests that this is indeed the case. In the Bonanno et al. (2002) study described earlier, chronic grievers showed significantly higher levels of dependency on their spouse as well as of general interpersonal dependency than did respondents in some of the other trajectory groups. It would be interesting to determine whether the nature of the relationship is an important risk factor in other kinds of relationships. For example, do parents have more difficulty resolving their grief following the death of an adolescent child if the relationship was conflictual?

Regarding personal and social resources, some of the most important work linking personality with bereavement outcome has been conducted by Nolen-Hoeksema and her colleagues (see, e.g., Nolen-Hoeksema \& Larson, 1999; Nolen-Hoeksema, 2001). In a study on coping with conjugal loss, she identified two personality variables that played an important role: dispositional optimism and a ruminative coping style. Those who scored high on dispositional optimism (i.e., the tendency to be optimistic in most circumstances) showed a greater decline in symptoms of depression following the loss, and were also more likely to find meaning or benefit in the loss than were pessimists. As mentioned earlier, a ruminative coping style involves a tendency to "engage in thoughts and behaviors that maintain one's focus on one's negative emotions and the possible causes and consequences of those emotions" (Nolen-Hoeksema, 2001, p. 546). NolenHoeksema's findings indicate that those who engage in rumination following loss show little decrease in distress over time. Although bereaved ruminators believe that their thoughts about the loss will help solve their problems, this is not the case: They are significantly less likely to become actively engaged in effective problem solving than are nonruminators.

In recent years, there has been increasing interest in the role that religious or spiritual beliefs may play in dealing with a loved one's death (see Stroebe $\&$ Schut, 2001, for a more detailed discussion). Many investigators have suggested that religious beliefs may ease the sting of death, and facilitate finding meaning in the loss, by providing a ready framework of beliefs for incorporating negative events (Pargament \& Park, 1995). It has also been argued that specific tenets of one's faith, such as the belief that the deceased is in a better place, or that 
the survivor and deceased will be reunited in the afterlife, may mitigate the distress associated with the death of a loved one. Unfortunately, most of the studies that have examined variables of this sort are methodologically weak, and the results are conflictual. However, there are indications in the literature that religious beliefs facilitate finding meaning in the death of a child (McIntosh, Silver, \& Wortman, 1993; Murphy, Johnson, \& Lohan, 2003). Moreover, available evidence suggests that those with spiritual beliefs are more likely to use positive reappraisal and effective problem solving than those who do not hold such beliefs (Richards et al., 1999; Richards \& Folkman, 1997).

As noted earlier, there is also a great deal of interest in the relationship between a person's attachment style and his or her reaction to the loss of a loved one (see Shaver \& Tancredy, 2001, and Stroebe, Schut, \& Stroebe, 2005a, for a more detailed discussion). For example, Shaver and Tancredy (2001) have maintained that individuals with a secure attachment style find it easy to be close to others, and typically react to loss with normal but not overwhelming grief. Those with an insecuredismissing orientation to relationships have difficulty trusting others or allowing themselves to depend on others, and are "compulsively independent" (Stroebe, Stroebe, \& Schut, in press, p. 21). These individuals would be expended to suppress and avoid attachment-related emotions, and to show relatively little distress following a major loss. Those with an anxious or preoccupied orientation to relationships have a strong desire to be close to others but are often preoccupied or worried that their partner will abandon them. Such individuals would be expected to react to the loss with intense distress and to remain upset and preoccupied with the loss. Although few studies have tested these hypotheses, some limited evidence suggests that attachment style may be important. For example, Wayment and Vierthaler (2002) found that persons with a secure attachment style showed lower levels of depressive symptoms following the loss of a loved one than those with a preoccupied style, who expressed more distress and were more likely to engage in rumination.

At present, some of the most exciting work on risk factors has focused on various factors associated with the context in which the death occurs. One contextual factor that is generating increasing research interest concerns the circumstances under which the death occurs. Accumulating evidence clearly suggests that grief is more likely to be intense and prolonged following the sudden, traumatic loss of a spouse or child.

In an early study examining the effects of losing a spouse or child in a motor vehicle accident 4 to 7 years previously (Lehman, Wortman, \& Williams, 1987), comparisons between the bereaved and control respondents, matched on a case-by-case basis, revealed significant differences on depression and other psychiatric symptoms, role functioning, and quality of life. The bereaved experienced more strain in dealing with surviving children and family members, and felt more vulnerable to future negative events. Bereavement was associated with an increased mortality rate, a decline in financial status, and, in the case of bereaved parents, a higher divorce rate. A majority of respondents indicated that they were still experiencing painful thoughts and memories about their loved one.

Another study focusing on how parents are affected by the sudden, traumatic loss of a child (Murphy et al., 2002) found that 5 years postloss, a majority of mothers and fathers met diagnostic criteria for mental distress. Compared with normative samples, about three times as many mothers (28\%) and twice as many fathers (13\%) met diagnostic criteria for post-traumatic stress disorder (PTSD). In a follow-up study, Murphy, Johnson, $\mathrm{Wu}$, et al. (2003) examined the influence of type of death (accident, suicide, homicide) and time since death on parent outcome. Those who lost a child through homicide were more likely to manifest symptoms of PTSD. However, a majority of parents reported that it took them 3 or 4 years to put the loss into perspective and continue with their lives, and this assessment was not affected by the child's cause of death.

Similar results were obtained in a study by Dyregrov et al. (2003), who focused on parents who lost a child as a result of suicide, sudden infant death syndrome (SIDS), or an accident. The results showed that one and a half years after the death of their child, a considerable proportion of parents showed symptoms of PTSD and complicated grief reactions. Rates of problems were highest for those who lost loved ones through accidents or suicide. As many as $78 \%$ of these parents were "above the risk zone of maladaptive symptoms of loss and long-term dysfunction" (p. 155). On the basis of these findings, the authors concluded that "to lose 
a child suddenly and in traumatic circumstances is a devastating experience for the survivors, most often resulting in a tremendous and long-lasting impact" (p. 156).

Available evidence also suggests that the sudden, traumatic death of a spouse is associated with intense and prolonged distress. In addition to the aforementioned study by Lehman et al., two more recent studies help to clarify the impact of such losses. Zisook, Chentsova-Dutton, and Shuchter (1998) followed a large number of respondents longitudinally for the first 2 years after losing a spouse. Those whose spouse died as a result of an accident, homicide, or suicide were more likely to develop PTSD symptoms than those who experienced a sudden, unexpected death due to natural causes (e.g., heart attack). Those who scored high on PTSD symptomology also scored high on depression. Similarly, Kaltman and Bonanno (2003) compared respondents whose spouses died of natural causes with those who experienced the death of a spouse as a result of an accident, homicide, or suicide. The latter group manifested a significantly higher number of PTSD symptoms as long as 25 months after the loss. Moreover, those who lost a loved one through natural causes showed a decline in depressive symptoms, whereas those who lost a loved one as a result of an accident or suicide showed no drop in depressive symptoms over the 2-year course of the study. Among the natural death cohort, there were no significant differences in PTSD symptoms or the persistence of depression between bereaved individuals who had sudden, unexpected losses and those who had expected losses.

Taken together, these studies provide compelling evidence that the death of a spouse or child under traumatic or violent circumstances is linked to more intense and prolonged grief. It is important to note that such deaths are associated with PTSD symptoms as well as symptoms of depression. This means that in addition to dealing with such symptoms as yearning for the deceased and profound sadness, survivors of sudden, traumatic losses must contend with such symptoms as intrusive thoughts and flashbacks, feelings of detachment or estrangement, irritability, and problems in concentration.

The studies reviewed here have focused primarily on the untimely death of a spouse or child. Do the circumstances under which the death occurs have an impact on survivors when a loved one dies following a life-threatening illness or when an elderly person dies? For people aged 65 and older, chronic illnesses such as cancer, heart disease, and diabetes account for more than $60 \%$ of all deaths. Over the past decade, a great deal of research has focused on the impact of caregiving (see Carr, Wortman, \& Wolff, 2006, for a review). Studies have shown that caregivers are more stressed and depressed and have lower levels of well-being than noncaregivers (Pinquart \& Sorensen, 2003a, 2003b). Depressive symptoms increase as the number of hours one engages in caregiving increases (Schulz et al., 2001). In recent years, investigators have begun to examine the impact of caregiving on adjustment to the loss following the loved one's death. This research demonstrates that the relationship between caregiving and adjustment to bereavement is complex. Although stressful caregiving is associated with poor psychological adjustment when the spouse is alive, overly taxed caregivers tend to rebound to relatively high levels of functioning after the loss (Schulz et al., 2003). A minority of strained caregivers demonstrated intense and prolonged grief, and investigators are attempting to uncover the determinants of this reaction. Caregivers who are most energized by their caregiving role, and who find meaning in what they are doing, often have a difficult time adjusting to the loss (Boerner, Schulz, \& Horowitz, 2004). These studies suggest that those who are at the greatest risk of distress during the dying process may fare relatively well in the post-loss period.

In an important paper, Carr (2003) has pointed out that policymakers and care providers are becoming increasingly concerned with helping dying people to experience a "good death." According to Carr (2003), a "good death" is characterized by physical comfort, support from one's loved ones, acceptance, and appropriate medical care. Carr is one of the first bereavement researchers to suggest whether a loved one dies a "good death" may have implications for the grief experienced by surviving family members. In analyses based on the Changing Lives of Older Couples (CLOC) data, she found that those who reported that their spouses were in severe pain showed elevated levels of yearning, anxiety, and intrusive thoughts following the loss. Those who believed that their spouse's medical care was negligent reported elevated anger symptoms.

Several studies have shown that there are unique stresses associated with caring for a loved one who 
is dying (see Carr et al., 2006, for a more detailed discussion). For example, Prigerson and her associates (2003) examined quality of life among hospice-based dying patients and their caregivers, who included spouses and children. The caregivers had cared for their relatives for 2 years, on average, prior to the hospice admission. More than three quarters of the caregivers reported that they had witnessed the patient in severe pain or discomfort, and $62 \%$ said they had witnessed this daily. Nearly half reported that their loved one was unable to sleep or unable to eat or swallow on a daily basis. These findings are particularly striking when one considers that one of the core goals of hospice care is pain management. Several studies have shown that family members report more positive evaluations of their spouse's quality of care at the end of life and better psychological adjustment following the death when their loved one spent his or her final weeks using in-home hospice services rather than receiving care in nursing homes, hospitals, or at home with home health nursing services (see, e.g., Teno, Clarridge, \& Casey, 2004). In fact, a study by Christakis and Iwashyna (2003) indicates that hospice use can reduce the increased mortality of risk associated with bereavement. These investigators conducted a matched cohort study with a sample of nearly 200,000 respondents in the United States. At 18 months after the loss, there were significantly fewer deaths among wives whose husbands had received hospice care than among those whose husbands received other types of care (typically a combination of home care with occasional hospital stays). Mortality was also lower for husbands whose wives received hospice care, but the effect fell short of statistical significance. These studies suggest that sites of care that provide hospice may be more conducive to a "good death" for the patient and, consequently, his or her surviving loved ones.

\section{Complicated Grief As a Distinct Psychiatric Disorder}

Despite the progress that has been made in identifying risk factors for chronic grief, there are no standard guidelines to determine how complications following bereavement should be diagnosed and when they should be treated. Among theorists as well as clinicians, there has been a long-standing awareness that bereavement can result in psychiatric problems. As Jacobs (1993) has indicated, most research has focused on the prevalence of clinically significant depression and anxiety disorders among the bereaved. More recently, as was described earlier, researchers have become interested in the prevalence of PTSD following the loss of a loved one, particularly among survivors of sudden, traumatic losses.

In an important new line of research, Prigerson and her associates (e.g., Prigerson, 2004; Jacobs, Mazure, \& Prigerson, 2000; see Lichtenthal, Cruess, $\&$ Prigerson, 2004, for a review) have focused on the empirical development of diagnostic criteria to identify those individuals who exhibit chronic grief, and who would benefit from clinical intervention. Drawing from epidemiological, pharmacological, and clinical case studies, these investigators have identified a unique pattern of symptoms called complicated grief (CG). They have maintained that these symptoms are associated with enduring mental and physical health problems that are typically slow to resolve, and that can persist for years if left untreated. Hallmark symptoms of CG include intense yearning for the deceased, difficulty accepting the death, inability to trust others or to feel close to them, excessive bitterness or anger related to the death, and feeling uneasy about moving on with one's life. To obtain a diagnosis of CG, individuals must experience a majority of these symptoms for at least 6 months, and the symptoms must cause marked and persistent dysfunction in social, occupational, or other important roles. Research has shown that these symptoms form a unified cluster and that they are distinct from depression, anxiety, or PTSD. For example, feeling sad and blue is characteristic of depression but not of CG, and avoidance and hyperarousal are characteristic of PTSD but not of CG. Unlike these other disorders, vulnerability to CG is believed to be rooted in insecure attachment styles that are developed in childhood. Consistent with this notion, evidence has shown that childhood abuse and serious neglect are significantly associated with CG during widowhood (Silverman, Johnson, \& Prigerson, 2001).

Evidence has shown that the prevalence of CG among individuals who have lost a loved one is between $10 \%$ and $20 \%$. The symptoms of CG typically last for several years. They are predictive of morbidity (e.g., suicidal thoughts and behaviors, incidence of cardiac events, high blood pressure), adverse health behaviors (e.g., increased alcohol consumption and use of tobacco), and impairments in the quality of life (e.g., loss of energy). Interest- 
ingly, bereaved people with CG are significantly less likely to visit a mental health or physical health care professional than those without grief complications; perhaps people with severe mental anguish have difficulty mobilizing themselves to go into treatment.

\section{Future Directions}

We now know that a significant minority of individuals experience enduring difficulties following the loss of a loved one, and we have a reasonably good understanding of the risk factors for grief complications. However, important questions remain unanswered about exactly how people do recover from a loss. As Archer (1999) has observed, "It is commonly believed that it is not time itself that is the healer but some process which occurs during this time" (p. 108). At this point, however, there is considerable confusion about what this process involves. It is now clear that some people recover from a loss without "working through" the implications of what has happened. What other processes play an important role in facilitating acceptance of what has happened, the ability to encounter reminders without distress, and the ability to become engaged in new interests and pursuits?

Among those who show enduring difficulties, it is important to clarify the extent to which these problems stem from the loss of a loved person, and the extent to which they stem from other losses or concurrent stressors. The death of child, for example, may require surviving parents to face the loss of their hopes and dreams for the future, the loss of their belief in God as a benevolent protector, and the loss of their beliefs in their ability to control outcomes that are important. The death of a spouse is often accompanied by concurrent stressors, including loss of income or struggling with tasks formerly performed by the deceased.

Although most research on the enduring effects of loss has focused on mental and physical health problems, there is increasing recognition that losses can bring about positive psychological changes (Tedeschi \& Calhoun, 1996, 2004). Several researchers have documented, for example, that following the loss of a spouse, the surviving spouse reports greater feelings of self-confidence, a greater awareness of one's strengths, and a greater inclination to try new experiences (see Wortman, 2004, for a review). It less clear whether sudden, traumatic losses of a spouse or child are accompanied by personal growth. There are some indications that survivors of trauma resent the implication that they should be able to find something good in what has happened, and that others' exhortations to this effect often heighten survivors' feelings of inadequacy and shame (see Wortman, 2004, for a more detailed discussion).

\section{Conclusions and Implications}

In previous papers, we have described several common assumptions about coping with loss that appear to be held by professionals in the field as well as by laypersons. We conducted a careful evaluation of each assumption and concluded that most were not supported, and were often contradicted, by the available data. Indeed, this is why these assumptions were originally referred to as "myths of coping with loss."

It has been almost 20 years since the first articles on the myths of coping appeared in the literature (Wortman \& Silver, 1987, 1989). As the scientific evidence pertaining to these myths has continued to accumulate, there have been some shifts in the prevailing views about how people cope with loss. The main purpose of this chapter has been to summarize the most important research bearing on the validity of each "myth of coping," and also to highlight how the myths themselves have changed over time. In the material to follow, we first summarize how, in our judgment, these assumptions are currently viewed by researchers. We then discuss the implications of the myths of coping for future research endeavors.

We then examine the extent to which the myths of coping are still influential among practicing clinicians. We discuss the relationship between belief in these myths and grief counseling and therapy as it is currently practiced in the United States today. In particular, we highlight extensive research evidence suggesting that treatment for grief is in most cases ineffective, and in some cases harmful. We then consider the extent to which the myths of coping are continuing to influence other health care providers who come into contact with the bereaved, such as clergy and general practitioners. Next, we consider the extent to which these myths of coping are maintained by the bereaved themselves and their potential support providers. Finally, we explore whether these beliefs impact the amount and quality of support the bereaved are likely to receive. 


\section{Implications for Research}

As empirical work on the variability in response to loss has continued to accumulate, it appears that researchers' assumptions about the process of coping with loss have changed in important ways. For example, most researchers would probably agree that a large minority of respondents fail to experience even mild depression following an important loss, that delayed grief is rare, that positive emotions are common following a loss and are associated with a good recovery, that not everyone may need to actively confront their thoughts and feelings about the loss, that continuing attachment to the loved one is normal, and that recovery from a loss is highly variable and depends on many factors, including the nature of the relationship and the circumstances surrounding the death.

Awareness of this body of work is leading researchers to ask new and important questions about the process of coping with loss. As was noted earlier, for example, many of the early studies on grief focused solely on depression and other negative emotions and symptoms; questions about positive emotions experienced during grieving were typically not included. At this point, however, researchers not only are including measures of positive emotions but also are attempting to identify the role that such emotions may play in facilitating adjustment to a loss. In terms of outcome measures, it has become clear that we must examine the possibility that losses can bring about enduring positive changes, such as increased self-confidence and independence, altered life priorities, and enhanced compassion for others suffering similar losses (for a more detailed discussion of growth following loss, see Wortman, 2004).

Despite these advances, it is important for researchers to ask themselves whether they may hold assumptions or beliefs about the coping process that are limiting the scope of their scientific inquiry into loss. In a collaborative study called the Americans' Changing Lives, for example (see Nesse, Wortman, $\&$ House, 2006), personal interviews were conducted with a national sample of people who had lost a spouse anywhere from 3 months to 60 years previously. Several of the investigators wanted to eliminate questions about widowhood for all respondents whose loss occurred longer than 10 years ago, assuming that there would be no effects after that point. Ultimately, the decision was made to ask these questions of all respondents. This was fortunate because the results enhanced our knowledge about the ways such losses continue to influence the surviving spouse. For example, several decades after the loss, it was common for people to have thoughts and conversations about their spouse that made them feel sad or upset (see Carnelley, Wortman, Bolger, \& Burke, in press).

\section{Implications for Treatment}

Earlier, we have attempted to argue that in most cases, researchers no longer take the prevailing cultural assumptions about coping with loss at face value and instead appear to recognize the extraordinary variability in response to loss. It is less clear, however, whether the accumulation of research findings has filtered down to clinicians or other health care providers working with the bereaved, to potential support providers of the bereaved, or to the bereaved themselves.

\section{Clinicians}

A review of books and articles written for and by clinicians indicates that assumptions about the importance of going through a period of distress, and of working through the loss, are still widely held. For example, in what is perhaps the most widely used book on grief counseling written for clinicians and other mental health professionals, Worden (2002) indicates that not allowing negative feelings to be experienced frequently leads to complicated bereavement. As he expressed it, "It is necessary to acknowledge and work through this pain or it can manifest itself through physical symptoms or some form of aberrant behavior" (p. 30).

There has been a proliferation of grief counseling and therapy, which is reflected in wide offerings of workshops, professional conferences, and publications, as well as in countless individual and group-based treatments offered in virtually all communities (Neimeyer, 2000). As Neimeyer (2000) has indicated, most people assume that grief counseling is "a firmly established, demonstrably effective service, which, like psychotherapy in general, seems to have found a secure niche in the health care field" (p. 542). And indeed, most clinicians who treat the bereaved believe that what they do is helpful and necessary (Jordan \& Neimeyer, 2003). Schut, Stroebe, van den Bout, and Terheggen (2001) published a narrative review of bereavement inter- 
vention studies, focusing separately on studies designed to prevent the development of problems in the general population of bereaved individuals, studies of individuals at high risk to develop complications, and studies of bereaved people who had already developed serious complications. Although these reviews have focused on somewhat different sets of studies and have employed a variety of analytic approaches, all have come to basically the same conclusion: that the scientific basis for the efficacy of grief counseling is quite weak (for a more detailed discussion of these reviews and their implications, see Jordan \& Neimeyer, 2003, and Stroebe, Schut, $\&$ Stroebe, 2005b).

All three of the studies using meta-analytic techniques found small effect sizes for bereavement interventions. For example, Neimeyer (2000) found an overall effect size of .13 across the 23 studies they included. This means that the average participant in grief therapy was better off than only $55 \%$ of bereaved people who received no treatment. This effect size is far smaller than the effect size for other types of therapeutic evaluations that have been studied. Moreover, they found clear evidence that such interventions can have a negative impact: They found that $38 \%$ of participants showed apparent deterioration as a result of the treatment and would have had a better outcome if they had been assigned to the control, rather than the treatment, condition. As Jordan and Neimeyer (2003) have noted, this rate is far higher than that obtained in most psychotherapy outcome studies, where there is an average rate of deterioration of about $5 \%$. Treatment outcome was not related to such variables as the length of treatment, the level of training of the therapist (professional vs. nonprofessional), or the type of treatment approach (individual, family, or group).

Fortner and Neimeyer (as reported in Neimeyer, 2000) did find a more substantial, but still modest, positive effect size (.38) among studies dealing with grief following a sudden, traumatic death or chronic grief, and the potential for deterioration was substantially lower for these groups (.17\%). Similar findings emerged from Schut et al.'s (2001) narrative review. Among those who were defined as being at high risk for developing bereavementrelated problems (e.g., those who had experienced the sudden, traumatic death of a loved one, those who lost a child, or those who evidenced high levels of symptoms prior to the intervention), a modest positive effect was found. Schut et al. (2001) found the most positive effects for those intervention studies that focused on bereaved individuals who had already developed a complicated grief reaction.

Jordan and Neimeyer (2003) have pointed out that there are many possible ways of understanding this pattern of findings. Some studies may have failed to find a robust positive effect for grief counseling because the studies were small, and there may not have been enough statistical power to detect differences between groups. In other studies, findings may not have emerged because the treatment offered did not include enough sessions (most included 8-12 sessions). Alternatively, the intervention may not have been offered at the most appropriate time. Neimeyer (2000) found that interventions that were delivered shortly after the death had significantly smaller effect sizes than those delivered at a later time. Jordan and Neimeyer (2003) have suggested that there may be a "critical window of time" (p. 774) when it is best to offer interventions, perhaps 6 to 18 months after the loss, "before problematic patterns of adjustment have become entrenched" (p. 774). These investigators also emphasized that the types of counseling needed shortly after the loss may differ from what is needed a year or more after the loss, noting that investigators should try to customize the type of intervention to particular points in the bereavement trajectory.

Taken together, these findings suggest that in many cases, people may not need therapy following a loved one's death, but that some subgroups are likely to benefit substantially from treatment. It would be useful to develop interventions that are designed specifically to address the problems of mourners in high-risk categories, such as those who have experienced the sudden, traumatic loss of a spouse or child, or those who have already developed complicated grief. Shear and her associates (2005) have recently completed a randomized, clinical trial comparing an intervention designed for people with complicated grief to a more standard treatment for depression (interpersonal therapy). The multifaceted complicated grief intervention draws from research on the treatment of PTSD. For example, clients are given exercises to help them confront avoided situations. In addition, they are asked to tell their story into a tape recorder and to play it back during the week. The average length of treatment was 19 weeks. Although both treatments produced improvement in complicated grief symptoms, there was a higher 
response rate and a faster time to response in the complicated grief treatment. This treatment would appear to hold considerable promise for people who are struggling with complicated grief.

Perhaps the main implication of this work for practicing clinicians is that they should not assume that one type of intervention will work best for everyone. As Jordan and Neimeyer (2003) have emphasized, "It is a truism that grief is unique to each individual, yet this wisdom is rarely reflected in the design and delivery of services to the bereaved" (p. 782). They suggest that treating clinicians focus more attention on such issues as whether the client has experienced previous traumas or losses, as well as the client's personality structure, coping style, and available support resources.

This work suggests that it is essential for program administrators to focus their efforts on identifying high-risk mourners. This task could be facilitated by the development of screening tools that make it possible to identify people at risk for subsequent problems. As was described earlier, Prigerson and her associates (1995) have developed an Inventory of Complicated Mourning that has predictive validity regarding those who are likely to develop complicated grief. It would be useful to have screening tools that could quickly and reliably assess other risk factors and resources, such as trauma history and available social support.

One consistent finding that has emerged from the intervention studies reviewed here is that those who seek treatment are likely to show better results from grief therapy than those who are recruited into a treatment (see Stroebe, Schut, \& Stroebe ., 2005b, for a more detailed discussion). It is not clear whether this occurs because those who seek treatment are more likely to have serious problems and hence benefit more from the treatment, or whether other important factors underlie this effect. However, as was noted earlier, there is evidence to indicate that individuals with complicated grief are less likely to seek treatment than those whose grief is not associated with complications. This suggests that those most in need of help may be least likely to seek and obtain it. At this point, little is known about what percentage of high-risk mourners seek help. It would also be highly useful to understand the reasons that high-risk mourners often do not seek help. Clearly, it is important for administrators and policymakers to find ways of reaching out to high-risk mourners who do not avail themselves of treatment.

\section{Other Care Providers}

Studies on help seeking among the bereaved have shown that only a small percentage of those who experience major mental health problems following bereavement seek professional help (see Jacobs, 1993, for a more detailed discussion). To the extent that they seek assistance at all, bereaved individuals are far more likely to approach physicians, nurses, or clergymen than they are to seek formal grief counseling or therapy. Hence, it is important to ask whether these care providers may hold assumptions about the grieving process that interfere with their ability to provide effective help and support to the bereaved.

There is evidence to suggest that physicians and nurses do not receive much training about grief, and an examination of commonly used textbooks suggests that such books often perpetuate the myths of coping. For example, books written for nurses and physicians frequently maintain that people go through stages of emotional response as they come to terms with the loss, and that failure to exhibit distress is indicative of a problem (see, e.g., Potter $\&$ Perry, 1997). Clearly, it is important for care providers to recognize that particularly with certain kinds of loss, it is normative to exhibit little distress, and that this may be indicative of resilience.

How much do physicians and clergy know about the risk factors associated with complications of bereavement? Do they know, for example, that a high percentage of parents who experience the sudden, traumatic loss of a child experience high levels of symptoms for years after the loss? If they are not aware of these findings, they may convey to bereaved parents that they should be over the loss, thus contributing to the burden such parents are already shouldering. In our experience, it is common for physicians and those in the clergy to assume that prolonged grief is indicative of a weakness or coping failure on the part of the bereaved. It is also important for physicians and clergymen to have a good understanding of the symptomology that accompanies particular types of loss. For example, they could be far more helpful to those who encounter sudden, traumatic losses if they understand that such losses are often accompanied by post-traumatic stress symptoms. Many studies have suggested that following the traumatic death of a loved one, survivors are frightened by such symptoms as loss of memory and concentration, 
and intrusive thoughts or images of the deceased (Dyregrov et al., 2003), Physicians and clergymen are in a unique position to normalize disturbing symptoms among bereaved who are not receiving grief therapy or treatment. Bereaved individuals are likely to benefit from learning that their symptoms are understandable, given what they have been through, and do not convey mental illness or coping failure.

Knowledge of risk factors not only would help to ensure that bereaved people are treated more compassionately by their physicians and clergymen but also would increase the likelihood that those who would benefit from counseling are encouraged to seek help. At present, little is known about how common it is for these care providers to make referrals, or whether they are knowledgeable about how or where to refer bereaved people for grief counseling.

Considering the impact of bereavement on mortality, particularly among men who lose their spouses, it would also be prudent for clergy to encourage these men to see their physicians. These men would benefit from encouragement, from physicians as well as clergymen, to take other positive steps to maintain their health. Clergymen may also be in a good position to mobilize support for the bereaved, particularly for widowed men who may have relied primarily on their wives for support and companionship.

\section{The Bereaved and Their Support Providers}

At the present time, what expectations or assumptions about the grieving process are prevalent among laypersons? When a person experiences a loss, does he or she expect to go through stages of grief, beginning with intense distress? If intense distress is not experienced, is this a source of concern? How knowledgeable are laypersons about the symptoms of grief, and how do they judge and evaluate their own reactions? Do they believe that it is necessary to "work through" the loss, and if so, what kinds of behaviors do they engage in to facilitate this? Do they assess their progress according to a timetable concerning when they think they should be recovered? Are laypersons aware that symptoms are more intense and prolonged following certain kinds of losses, or do they hold themselves up to unrealistically high standards and judge themselves harshly if they are not able to move on within a year or so? Given that most bereaved do not seek grief counseling or therapy, where do they turn for assistance, and to what extent are they able to obtain information and/or support that is beneficial? It is also important to ascertain whether certain assumptions or beliefs about coping with loss are held by members of the bereaved person's support network and, if so, whether these facilitate or impede the receipt of effective support.

Unfortunately, few studies have focused on these questions, and at present little is known about how the grief process is viewed by the bereaved, or by those in their support network. However, there are some indications in the literature that many laypersons still believe in stages of emotional response. Elison and McGonigle (2003) describe a case in which one woman asked her therapist to do something to make her angry. When the therapist asked why she should do so, the client replied, "My neighbor told me that at this stage, I should be angry, and I'm not. "I'm afraid I'm not doing this right" (p. xxiii).

It also appears that laypersons have strong expectations that the bereaved will go through a period of intense distress. Those who do not appear to be showing enough distress may elicit judgmental reactions from others. A person who fails to react with sufficient distress may also be thought to be "in denial," with friends conveying the sentiment that "it hasn't hit her yet." Elison and McGonigle (2003) have pointed out that in cases of deaths that occur under suspicious circumstances, failure to show distress may be shown as evidence as guilt. They maintained that the failure of John and Patty Ramsey to show distress following the murder of their daughter, JonBenet, "convicted them in the court of public opinion."

In their insightful book Liberating Losses, Elison and McGonigle (2003) describe several situations in which people feel relieved or liberated following the loss of a loved one. For example, they note that it is common to experience feelings of relief after a long period of caregiving. Such feelings are also prevalent when a person has been involved in a relationship with someone who has been a constant source of criticism, abuse, or oppression. In these cases, the death may be viewed as a "God given divorce" (see also Sanders, 1999). Elison and McGonigle (2003) note how outsiders' comments are often unhelpful. For example, a friend may say "it's okay to cry," or "You must miss him terribly," 
thus making the survivor feel even more guilty and conspicuous. Or they may make comments like, "I can't believe you're getting rid of his things already," implying that the survivor's reactions are inappropriate.

Regarding expectations about recovery, some studies suggest that the bereaved judge themselves harshly if they continue to show intense distress beyond the first few months. A frequent complaint of the bereaved is that others expect them to be recovered from the loss after the first few months or so. There is also evidence that others attempt to encourage a prompt recovery following the loss, and that the bereaved do not find this helpful (Ingram et al., 2001; Lehman, Ellard, \& Wortman, 1986). For example, following the death of a spouse, friends might try to arouse the surviving spouse's interest in new activities or in the resumption of old hobbies or interests. It is also common for others to bring up the topic of remarriage. Discussions of this topic are often initiated within a few days or weeks of the spouse's death.

Other kinds of responses that are frequently made by potential support providers but that are not regarded as helpful by the bereaved include attempts to block discussions about the loss or displays of feelings (e.g., "Crying won't bring him back"); minimization of the problem (e.g., "You had so many good years together"); invoking a religious or philosophical perspective (e.g., "God needed him more than you did"); giving advice (e.g., "You should consider getting a dog; they're wonderful companions"); and identification with feelings (e.g., "I know how you feel-I lost my second cousin"). It is also common for those in the support network to ask inappropriate questions. They may ask about such matters as how the death occurred (e.g. "Was he wearing a seat belt?"); about financial matters (e.g., "How are you going to spend all of that insurance money?"); or about the loved one's possessions (e.g., "What are you going to do with his tools?"). Studies have shown that unsupportive social interactions account for a significant amount of the variance in depression among the bereaved, beyond the variance explained by the level of present grief (Ingram et al., 2001). Such comments are more likely to be made by relatives or close friends than they are among casual acquaintances of the survivor (see Wortman, Wolff, \& Bonanno, 2004, for a more detailed discussion).
What types of responses from support providers do the bereaved regard as beneficial? Research indicates that they value the opportunity to talk with others about their feelings when they elect to do so (Lehman et al., 1986; Marwit \& Carusa, 1998). In fact, there is evidence that if people want to talk about the loss and are blocked from doing so, they become more depressed over time (Lepore et al., 1996). The bereaved also find it helpful when others convey a supportive presence (e.g., "I am here for you") or express concern (e.g., "I care what happens to you"). Tangible assistance, such as help with errands or meals, is typically regarded as helpful. Finally, contact with a similar other is judged to be very helpful. Unlike those who have not experienced such a loss, they may have a more accurate understanding of what the bereaved has been through. Contact with similar others can also reassure the bereaved that their own feelings and behaviors are normal.

In our judgment, it would be beneficial for the bereaved themselves, and their potential support providers, to have greater awareness of the extraordinary variability in responses to loss. We believe that awareness of the conditions under which the bereaved may fail to experience or exhibit distress, or may experience grief that is more intense and prolonged than the norm, would also have a positive impact. Hopefully, greater understanding of the available research will result in treatment of the bereaved that is less judgmental and more facilitative of their healing and growth.

\section{References}

Archer, J. (1999). The nature of grief: The evolution and psychology of reactions to loss. New York: Routledge.

Attig, T. (1996). How we grieve: Relearning the world. New York: Oxford University Press.

Attig, T. (2000). Anticipatory mourning and the transition to loving in absence. In T. A. Rando (Ed.), Clinical dimensions of anticipatory mourning: Theory and practice in working with dying, their loved ones, and their caregivers (pp. 115-133). Champaign, IL: Research Press.

Balk, D. (1983). Adolescents' grief reactions and selfconcept perceptions following sibling death: A study of 33 teenagers. Journal of Youth and Adolescence, 12, 137-161.

Baltes, M. M., \& Skrotzki, E. (1995). Tod im Alter: Eigene Endlichkeit und Partnerverlust [Death in 
old age: Finality and loss of spouse]. In R. Oerter \& L. Montada (Eds.), Entwicklungspsychologie (3rd ed., pp. 1137-1146). Munich, Germany: PVU.

Batten, M., \& Oltjenbruns, K. A. (1999). Adolescent sibling bereavement as a catalyst for spiritual bereavement as a catalyst for spiritual development: A model for understanding. Death Studies, 23, 529-546.

Belitsky, R., \& Jacobs, S. (1986). Bereavement, attachment theory, and mental disorders. Psychiatric Annals, 16, 276-280.

Bisconti, T. L., Bergeman, C. S., \& Boker, S. M. (2004). Social support as a predictor of variability: An examination of recent widows' adjustment trajectories. Manuscript submitted for publication.

Boerner, K., \& Heckhausen, J. (2003). To have and have not: Adaptive bereavement by transforming mental ties to the deceased. Death Studies, 27, 199-226.

Boerner, K., Schulz, R., \& Horowitz, A. (2004). Positive aspects of caregiving and adaptation to bereavement. Psychology and Aging, 19, 668-675.

Boerner, K., \& Wortman, C. B., \& Bonanno, G. (2005). Resilient or at risk? A four-year study of older adults who initially showed high or low distress following conjugal loss. Journal of Gerontology: Series B: Psychological Sciences and Social Sciences, 60B, P67-P73.

Bonanno, G. A. (2001). Grief and emotion: A socialfunctional perspective. In M. S. Stroebe \& R. O. Hansson (Eds.), Handbook of bereavement research: Consequences, coping, and care (pp. 493-515). Washington, DC: American Psychological Association.

Bonanno, G. A. (2005). Resilience in the face of potential trauma. Current Directions in Psychological Science, 14, 135-138.

Bonanno, G. A., \& Field, N. P. (2001). Evaluating the delayed grief hypothesis across 5 years of bereavement. American Behavioral Scientist, 44, 798-816.

Bonanno, G. A., \& Kaltman, S. (1999). Toward an integrative perspective on bereavement. Psychological Bulletin, 125, 760-786.

Bonanno, G. A., \& Kaltman, S. (2001). The varieties of grief experience. Clinical Psychology Review, 21, 705-734.

Bonanno, G. A., \& Keltner, D. (1997). Facial expressions of emotion and the course of conjugal bereavement. Journal of Abnormal Psychology, 106, 126-137.

Bonanno, G. A., Keltner, D., Holen, A., \& Horowitz, M. J. (1995). When avoiding unpleasant emotion might not be such a bad thing: Verbal-autonomic response dissociation and midlife conjugal bereavement. Journal of Personality and Social Psychology, 46, 975-985.

Bonanno, G. A., Mihalecz, M. C., \& LeJeune, J. T. (1999). The core emotion themes of conjugal loss. Motivation and Emotion, 23, 175-201.

Bonanno, G. A., Moskowitz, J. T., Papa, A., \& Folkman, S. (2005). Resilience to loss in bereaved spouses, bereaved parents, and bereaved gay men. Journal of Personality and Social Psychology, 88, 827-843.

Bonanno, G. A., Papa, A., Lalande, K., Zhang, N., \& Noll, J. G. (2005). Grief processing and deliberate grief avoidance: A prospective comparison of bereaved spouses and parents in the United States and the People's Republic of China. Journal of Consulting and Clinical Psychology, 73, 86-98.

Bonanno, G. A., Rennicke, C., \& Dekel, S. (in press). Self-enhancement among high-exposure survivors of the September 11th terrorist attack: Resilience or social maladjustment? Journal of Personality and Social Psychology.

Bonanno, G. A., Wortman, C. B., Lehman, D., Tweed, R., Sonnega, J., Carr, D., et al. (2002). Resilience to loss, chronic grief, and their pre-bereavement predictors. Journal of Personality and Social Psychology, 83, 1150-1164.

Bonanno, G. A., Wortman, C. B., \& Nesse, R. M. (2004). Prospective patterns of resilience and maladjustment during widowhood. Psychology and Aging, 19, 260-271.

Bournstein, P. E., Clayton, P. J., Halikas, J. A., Maurice, W. L., \& Robins, E. (1973). The depression of widowhood after thirteen months. British Journal of Psychiatry, 122, 561-566.

Bower, J. E., Kemeny, M. E., Taylor, S. E., \& Fahey, J. L. (2003). Finding positive meaning and its association with natural killer cell cytotoxicity among participants in a bereavement-related disclosure intervention. Annals of Behavioral Medicine, 25, 146-155.

Bowlby, J. (1969). Attachment. (Attachment and loss, Vol. 1). New York: Basic Books.

Bowlby, J. (1973). Separation: Anxiety and anger. (Attachment and loss, Vol. 2). New York: Basic Books.

Bowlby, J. (1980). Loss: Sadness and depression. (Attachment and loss, Vol. 3). New York: Basic Books.

Bruce, M. L., Kim, K, Leaf, P. J., \& Jacobs, S. (1990). Depressive episodes and dysphoria resulting from conjugal bereavement in a prospective community sample. American Journal of Psychiatry, 147, 608-611.

Carnelley, K. B., Wortman, C. B., Bolger, N., \& Burke, C. T. (in press). The time course of adjustment to 
widowhood: Evidence from a national probability sample. Journal of Personality and Social Psychology. Carnelley, K. B., Wortman, C. B., \& Kessler, R. C. (1999). The impact of widowhood on depression: Findings from a prospective survey. Psychological Medicine, 29, 1111-1123.

Carr, D. (2003). A "good death" for whom? Quality of spouse's death and psychological distress among older widowed persons. Journal of Health and Social Behavior, 44, 215-232.

Carr, D. (2004). Black/white differences in psychological adjustment to spousal loss among older adults. Research on Aging, 26, 591-622.

Carr, D., House, J. S., Kessler, R. C., Nesse, R. M., Sonnega, J., \& Wortman, C. (2000). Marital quality and psychological adjustment to widowhood among older adults: A longitudinal analysis. Journal of Gerontology: Series B: Psychological Sciences and Social Sciences, 55B,S197-S207.

Carr, D., Wortman, C. B., \& Wolff, K. (2006). How Americans die. In D. Carr, R. Nesse, \& C. B. Wortman (Eds.), Spousal bereavement in late life (pp. 49-78). New York: Springer.

Christakis, N., \& Iwashyna, T. (2003). The health impact on health care on families: A matched cohort study of hospice use by decedents and mortality outcomes in surviving, widowed spouses. Social Science and Medicine, 57, 465-574.

Cleiren, M. P. H. D. (1993). Bereavement and adaptation: A comparative study of the aftermath of death. Philadelphia: Hemisphere.

Cleiren, M., Diekstra, R., Kerkhof, A., \& van der Wal, J. (1994). Mode of death and kinship in bereavement: Focusing on "who" rather than "how." Crisis, 15(1), 22-36.

Datson, S. L., \& Marwit, S. J. (1997). Personality constructs and perceived presence of deceased loved ones. Death Studies, 21, 131-146.

Deutsch, H. (1937). Absence of grief. Psychoanalytic Quarterly, 6, 12-22.

Dyregrov, K., Nordanger, D., \& Dyregrov, A. (2003). Predictors of psychosocial distress after suicide, SIDS and accidents. Death Studies, 27, 143-165.

Elison, J., \& McGonigle, C. (2003). Liberating losses: When death brings relief. Cambridge, MA: Perseus

Field, N. P., \& Friedrichs, M. (2004). Continuing bonds in coping with the death of a husband. Death Studies, 28, 597-620.

Field, N. P., Gal-Oz, E., \& Bonanno, G. A. (2003). Continuing bonds and adjustment at 5 years after the death of a spouse. Journal of Consulting and Clinical Psychology, 71, 110-117.

Field, N. P., Nichols, C., Holen, A., \& Horowitz, M. J. (1999). The relation of continuing attachment to adjustment in conjugal bereavement. Journal of Consulting and Clinical Psychology, 67, 212-218.
Fleming, S., \& Robinson, P. J. (1991). The application of cognitive therapy to the bereaved. In T. M. Vallis \& J. L. Howes (Eds.), The challenge of cognitive therapy: Applications to nontraditional populations (pp. 135-158). New York: Plenum.

Folkman, S. (1997a). Introduction to the special section: Use of bereavement narratives to predict well-being in gay men whose partner died of AIDS-Four theoretical perspectives. Journal of Personality and Social Psychology, 72, 851-854.

Folkman, S. (1997b). Positive psychological states and coping with severe stress. Social Science and Medicine, 45, 1207-1221.

Folkman, S. (2001). Revised coping theory and the process of bereavement. In M. S. Stroebe \& R. O. Hansson (Eds.), Handbook of bereavement research: Consequences, coping, and care (pp. 563-584). Washington, DC: American Psychological Association.

Folkman, S., Chesney, M., Collette, L., Boccellari, A., $\&$ Cooke, M. (1996). Postbereavement depressive mood and its prebereavement predictors in HIV+ and HIV-gay men. Journal of Personality and Social Psychology, 70, 336-348.

Folkman, S., \& Moskowitz, J. T. (2000). Stress, positive emotion, and coping. Current Directions in Psychological Science, 9, 115-118.

Fraley, R. C., \& Shaver, P. R. (1999). Loss and bereavement: Bowlby's theory and recent controversies concerning "grief work" and the nature of detachment. In J. Cassidy \& P. R. Shaver (Eds.), Handbook of attachment theory and research: Theory, research, and clinical applications (pp. 735-759). New York: Guilford.

Fredrickson, B. L. (1998). What good are positive emotions? Review of General Psychology, 2, 300319.

Fredrickson, B. L. (2001). The role of positive emotions in positive psychology: The broadenand-build theory of positive emotions. American Psychologist, 56, 218-226.

Fredrickson, B. L., Tugade, M. M., Waugh, C. E., \& Larkin, G. R. (2003). What good are positive emotions? A prospective study of resilience and emotions following the terrorist attacks on the United States on September 11, 2001. Journal of Personality and Social Psychology, 84, 365-376.

Freud, S. (1917/1957). Mourning and melancholia. In J. Strachey (Ed.), The standard edition of the complete works of Sigmund Freud (Vol. 14, pp. 152-170). London: Hogarth Press.

Glick, I. O., Weiss, R. S., \& Parkes, C. M. (1974). The first year of bereavement. New York: Wiley.

Gowell, E. C. (1992). Good grief rituals: Tools for healing. New York: Station Hill Press.

Hagman, G. (1995). Mourning: A review and 
reconsideration. International Journal of PsychoAnalysis, 76, 909-925.

Hagman, G. (2001). Beyond decathexis: Toward a new psychoanalytic understanding and treatment of mourning. In R. A. Neimeyer (Ed.), Meaning, reconstruction and the experience of loss ( $\mathrm{pp} .13-$ 31). Washington, DC: American Psychological Association.

Hogan, N. S., \& DeSantis, L. (1994). Things that help and hinder adolescent sibling bereavement. Western Journal of Nursing Research, 16, 132-153.

Horowitz, M. J. (1976). Stress response syndromes. Oxford, England: Jason Aronson.

Horowitz, M. J. (1985). Anxious states of mind induced by stress. In A. H. Tuma \& J. D. Maser (Eds.), Anxiety and the anxiety disorders (pp. 619631). Hillsdale, NJ: Erlbaum.

Horowitz, M. J. (1990). A model of mourning: Change in schemas of self and other. Journal of American Psychoanalytic Association, 38, 297-324.

Ingram, K. M., Jones, D. A., \& Smith, N. G. (2001). Adjustment among people who have experienced AIDS-related multiple loss: The role of unsupportive social interactions, social support, and coping. Omega: Journal of Death and Dying, 43, 287-309.

Jacobs, S. (1993). Pathological grief: Maladaptation to loss. Washington, DC: American Psychiatric Press.

Jacobs, S., Mazure, C., \& Prigerson, H. (2000). Diagnostic criteria for traumatic grief. Death Studies, 24, 185-199.

Jordan, J. R., \& Neimeyer, R. A. (2003). Does grief counseling work? Death Studies, 27, 765-786.

Kaltman, S., \& Bonanno, G. A. (2003). Trauma and bereavement: Examining the impact of sudden and violent death. Journal of Anxiety Disorders, 17, 131-147.

Keltner, D., \& Bonanno, G. A. (1997). A study of laughter and dissociation: Distinct correlates of laughter and smiling during bereavement. Journal of Personality and Social Psychology, 73, 687-702.

Klass, D., Silverman, P. R., \& Nickman, S. L. (1996). Continuing bonds: New understandings of grief. Philadelphia: Taylor and Francis.

Klass, D., \& Walter, J. (2001). Processes of grieving: How bonds are continued. In M. S. Stroebe \& R. O. Hansson (Eds.), Handbook of bereavement research: Consequences, coping, and care (pp. 431448). Washington, DC: American Psychological Association.

Kovac, S. H., \& Range, L. M. (2000). Writing projects: Lessening undergraduates' unique suicidal bereavement. Suicide and Life-Threatening Behavior, 30, 50-60.

Kübler-Ross, E. (1969). On death and dying. New York: Springer.
Lazare, A. (1989). Bereavement and unresolved grief. In A. Lazare (Ed.), Outpatient psychiatry: Diagnosis and treatment (2nd ed., pp. 381-397). Baltimore: Williams and Wilkins.

Lazarus, R., \& Folkman, S. (1984). Stress, appraisal, and coping. New York: Springer.

Lazarus, R. S., Kanner, A. D., \& Folkman, S. (1980). Emotions: A cognitive-phenomenological analysis. In R. Plutchik \& H. Kellerman (Eds.), Emotions: Theory, research, and experience (Vol. 1, pp. 189-217). New York: Academic Press.

Lehman, D. R., Ellard, J. H., \& Wortman, C. B. (1986). Social support for the bereaved: Recipients' and providers' perspectives on what is helpful. Journal of Consulting and Clinical Psychology, 54, 438-446.

Lehman, D. R., Wortman, C. B., \& Williams, A. F. (1987). Long-term effects of losing a spouse or child in a motor vehicle crash. Journal of Personality and Social Psychology, 52, 218-231.

Lepore, S. J., Silver, R. C., Wortman, C. B., \& Wayment, H. A. (1996). Social constraints, intrusive thoughts, and depressive symptoms among bereaved mothers. Journal of Personality and Social Psychology, 70, 271-282.

Lepore, S. J., \& Smyth, J. M. (2002). The writing cure: How expressive writing promotes health and emotional well-being. Washington: American Psychological Association.

Lichtenstein, P., Gatz, M., Pedersen, N. L., Berg, S., \& McClearn, G. E. (1996). A co-twin control study of response to widowhood. Journal of Gerontology. Series B, Psychological Sciences and Social Sciences, 51, 279-289.

Lichtenthal, W. G., Cruess, D. G., \& Prigerson, H. G. (2004). A case for establishing complicated grief as a distinct mental disorder in DSM-V. Clinical Psychology Review, 24, 637-662.

Lopata, H. Z. (1979). Women as widows: Support systems. New York: Elsevier.

Lumley, M. A., Tojeck, T. M., \& Macklem, D. J. (2002). The effects of written and verbal disclosure among repressive and alexithymic people. In S. J. Lepore \& J. M. Smyth (Eds.), The writing cure: How expressive writing promotes health and emotional well-being (pp. 75-95). Washington, DC: American Psychological Association.

Lund, D. A., Dimond, M. F., Caserta, M. S., Johnson, R. J., Poulton, J. L., \& Connelly, J. R. (19851986). Identifying elderly with coping difficulties after two years of bereavement. Omega, 16, 213224.

Lund, D. A., Caserta, M. S., \& Dimond, M. F. (1986). Impact of bereavement on the self-conceptions of older surviving spouses. Symbolic Interaction, 9, 235-244. 
Malkinson, R. (2001). Cognitive-behavioral therapy of grief: A review and application. Research on Social Work Practice, 11, 671-698.

Malkinson, R., Rubin, S. S., \& Witztum, E. (2000). Traumatic and nontraumatic loss and bereavement: Clinical theory and practice. Madison, CT: Psychosocial Press.

Marris, P. (1958). Widows and their families. London: Routledge and Kegan Paul.

Martin, J. L, \& Doka, K. (2000). Men don't cry ... women do: Transcending gender stereotypes of grief. Philadelphia: Brunner/Mazel.

Marwit, S. J., \& Carusa, S. S. (1998). Communicated support following loss: Examining the experiences of parental death and parental divorce in adolescence. Death Studies, 22, 237-255.

Marwit, S. J., \& Klass, D. (1996). Grief and the role of the inner representation of the deceased. In D. Klass \& P. R. Silverman (Eds.), Continuing bonds: New understandings of grief (pp. 297-309). Philadelphia: Taylor and Francis.

McIntosh, D., Silver, R., \& Wortman, C. B. (1993). Religion's role in adjustment to a negative life event: Coping with the loss of a child. Journal of Personality and Social Psychology, 65, 812-821.

Mendes de Leon, C. F., Kasl, S. V., \& Jacobs, S. (1994). A prospective study of widowhood and changes in symptoms of depression in a community sample of the elderly. Psychological Medicine, 24, 613-624.

Middleton, W., Burnett, P., Raphael, B., \& Martinek, N. (1996). The bereavement response: A cluster analysis. British Journal of Psychiatry, 169, 167171.

Middleton, W., Moylan, A., Raphael, B., Burnett, P., \& Martinek, N. (1993). An international perspective on bereavement related concepts. Australian and New Zealand Journal of Psychiatry, 27, 457-463.

Middleton, W., Raphael, B., Burnett, P., \& Martinek, N. (1998). A longitudinal study comparing bereavement phenomena in recently bereaved spouses, adult children and parents. Australian and New Zealand Journal of Psychiatry, 32, 235-241.

Miller, E. D., \& Omarzu, J. (1998). New directions in loss research. In J. Harvey (Ed.), Perspectives on loss: A sourcebook (pp. 3-20). Washington, DC: Taylor \& Francis.

Miller, E., \& Wortman, C. B. (2002). Gender differences in mortality and morbidity following a major stressor: The case of conjugal bereavement. In G. Weidner, S. M. Kopp, \& M. Kristenson (Eds.), Heart disease: Environment, stress and gender. NATO Science Series, Series I: Life and Behavioural Sciences. Volume 327. Amsterdam: IOS Press.
Moskowitz, J. T., Folkman, S., \& Acree, M. (2003). Do positive psychological states shed light on recovery from bereavement? Findings from a 3-year longitudinal study. Death Studies, 27, 471500 .

Moskowitz, J. T., Folkman, S., Collette, L., \& Vittinghoff, E. (1996). Coping and mood during AIDS-related caregiving and bereavement. Annals of Behavioral Medicine, 18, 49-57.

Murphy, S. A. (1996). Parent bereavement stress and preventive intervention following the violent deaths of adolescent or young adult children. Death Studies, 20, 441-452.

Murphy, S. A., Das Gupta, A., Cain, K. C., Johnson, L. C., Lohan, J., Wu, L., et al. (1999). Changes in parents' mental distress after the violent death of an adolescent or young adult child: A longitudinal prospective analysis. Death Studies, 23, 129-159.

Murphy, S. A., Johnson, L. C., Chung, I., \& Beaton, R. D. (2003). The prevalence of PTSD following the violent death of a child and predictors of change 5 years later. Journal of Traumatic Stress, $16,17-25$.

Murphy, S. A., Johnson, L. C., \& Lohan, J. (2002). The aftermath of the violent death of a child: An integration of the assessment of parents' mental distress and PTSD during the first 5 years of bereavement. Journal of Loss and Trauma, 7, 203222.

Murphy, S. A., Johnson, L. C., \& Lohan, J. (2003). Finding meaning in a child's violent death: A fiveyear prospective analysis of parents' personal narratives and empirical data. Death Studies, 27, 381-404.

Murphy, S. A., Johnson, L. C., Wu, L., Fan, J. J., \& Lohan, J. (2003). Bereaved parents' outcomes 4 to 60 months after their children's death by accident, suicide, or homicide: A comparative study demonstrating differences. Death Studies, 27, 39-61.

Neimeyer, R. A. (1997). Problems and prospects in constructivist psychotherapy. Journal of Constructivist Psychology, 10, 51-74.

Neimeyer, R. A. (1998). Lessons of loss: A guide to coping. Boston: McGraw-Hill.

Neimeyer, R. A. (1999). Narrative strategies in grief therapy. Journal of Constructivist Psychology, 12, 65-85.

Neimeyer, R. A. (2000). Searching for the meaning of meaning: Grief therapy and the process of reconstruction. Death Studies, 24, 541-558.

Neimeyer, R. A. (2001). Meaning, reconstruction and the experience of loss. Washington, DC: American Psychological Association.

Neimeyer, R. A. (2006). Widowhood, grief and the quest for meaning: A narrative perspective on 
resilience. In D. Carr, R. M. Nesse, \& C. B. Wortman (Eds.), Spousal bereavement in late life (pp. 227-252). New York: Springer.

Nesse, R. M., Wortman, C. B., \& House, J. S. (2006). Introduction: A history of the Changing Lives of Older Couples Study. In D. Carr, R. Nesse, \& C. B. Wortman (Eds.), Spousal Bereavement in Late Life (pp. xxi-xxxi). New York: Springer.

Nolen-Hoeksema, S. (1991). Responses to depression and their effects on the duration of depressive episodes. Journal of Abnormal Psychology, 100, 569-582.

Nolen-Hoeksema, S. (2001). Ruminative coping and adjustment to bereavement. In M. S. Stroebe \& R. O. Hansson (Eds.), Handbook of bereavement research: Consequences, coping, and care (pp. 545562). Washington, DC: American Psychological Association.

Nolen-Hoeksema, S., \& Larson, J. (1999). Coping with loss. Mahwah, NJ: Erlbaum.

Nolen-Hoeksema, S., McBride, A., \& Larson, J. (1997). Rumination and psychological distress among bereaved partners. Journal of Personality and Social Psychology, 72, 855-862.

Norman, S. A., Lumley, M. A., Dooley, J. A., \& Diamond, M. P. (in press). For whom does it work? Moderators of the effects of written emotional disclosure in women with chronic pelvic pain. Psychosomatic Medicine.

Normand, C. L., Silverman, P. R., \& Nickman, S. L. (1996). Bereaved children's changing relationships with the deceased. In D. Klass \& P. R. Silverman (Eds.), Continuing bonds: New understandings of grief (pp. 87-111). Philadelphia: Taylor and Francis.

Ong, A. D., Bergeman, C. S., \& Bisconit, T. L. (2004). The role of daily positive emotions during conjugal bereavement. Journals of Gerentology: Series B: Psychological Sciences and Social Psychology, 59B, 168-176.

Osterweis, M., Solomon, F., \& Green, F. (1984). Bereavement: Reactions, consequences, and care. Washington, DC: National Academy Press.

Pargament, K. I., \& Park, C. L. (1995). Merely a defense? The variety of religious means and ends. Journal of Social Issues, 51, 13-32.

Parkes, C. M., \& Weiss, R. S. (1983). Recovery from bereavement. New York: Basic Books.

Pennebaker, J. W., \& Beall, S. K. (1986). Confronting a traumatic event: Toward an understanding of inhibition and disease. Journal of Abnormal Psychology, 95, 274-281.

Pennebaker, J. W., Zech, E., \& Rime, B. (2001). Disclosing and sharing emotion: Psychological, social, and health consequences. In M. S. Stroebe $\&$ R. O. Hansson (Eds.), Handbook of bereavement research: Consequences, coping, and care (pp. 517543). Washington, DC: American Psychological Association.

Pinquart, M., \& Sorenson, S. (2003a). Differences between caregivers and noncaregivers in psychological health and physical health: A metaanalysis. Psychology and Aging, 18, 250-267.

Pinquart, M., \& Sorenson, S. (2003b). Associations of stressors and uplifts of caregiving with caregiver burden and depressive mood: A meta-analysis. Journals of Gerentology: Series B: Psychological Sciences and Social Sciences, 58B, P112-P128.

Potter, P. A., \& Perry, A. G. (1997). Fundamentals of nursing: Concepts, process, and practice (4th ed.). St. Louis, MO: Mosby.

Prigerson, H. (2004). Complicated grief: When the path of adjustment leads to a dead-end. Bereavement Care, 23, 38-40.

Prigerson, H. G., Cherlin, E., Chen, J. H., Kasl, S. V., Hurzeler, R., \& Bradley, E. H. (2003). The stressful caregiving adult reactions to experiences of dying (SCARED) scale: A measure for assessing caregiver exposure to distress in terminal care. American Journal of Geriatric Psychiatry, 11, 309319.

Prigerson, H. G., Maciejewski, P. K., Reynolds, C. F., III, Bierhals, A. J., Newsom, J. T., Fasiczka, A., et al. (1995). Inventory of Complicated Grief: A scale to measure maladaptive symptoms of loss. Psychiatry Research, 59(1-2), 65-79.

Ramsay, R. W., \& Happee, J. A. (1977). The stress of bereavement: Components and treatment. In C. D. Spielberger, \& I. G. Sarason (Eds.), Stress and anxiety: IV (pp. 53-64). Oxford, UK: Hemisphere.

Rando, T. A. (1984). Grief, dying, and death. Champaign, IL: Research Press.

Rando, T. A. (1993). Treatment of complicated mourning. Champaign, IL: Research Press.

Range, L. M., Kovac, S. H., \& Marion, M. S. (2000). Does writing about the bereavement lessen grief following sudden, unintentional death? Death Studies, 24, 115-134.

Raphael, B. (1983). The anatomy of bereavement. New York: Basic Books.

Raphael, B., \& Nunn, K. (1988). Counseling the bereaved. Journal of Social Issues, 44, 191-206.

Rees, W. D. (1971). The hallucinations of widowhood. British Medical Journal, 4, 37-41.

Richards, T., Acree, M., \& Folkman, S. (1999). Spiritual aspects of loss among partners of men with AIDS: Postbereavement follow-up. Death Studies, 23, 105-127.

Richards, T. A., \& Folkman, S. (1997). Spiritual aspects of loss at the time of a partner's death from AIDS. Death Studies, 21, 527-552. 
Russac, R. J., Steighner, N. S., \& Canto, A. (2002). Grief work versus continuing bonds: A call for paradigm integration or replacement? Death Studies, 26, 463-478.

Sanders, C. M. (1989). Grief: The mourning after. New York: Wiley.

Sanders, C. M. (1993). Risk factors in bereavement outcome. In M. Stroebe, W. Stroebe, \& R. O. Hansson (Eds.), Handbook of bereavement: Theory, research and intervention (pp. 255-267). New York: Cambridge University Press.

Sanders, C. M. (1999). Grief: The mourning after (2nd ed.). New York: Wiley.

Schulz, R., Beach, S. R., Lind, B., Martire, L. M., Zdaniuk, B., Hirsch, C., et al. (2001). Involvement in caregiving and adjustment to death of a spouse: Findings from the caregiver health effects study. Journal of the American Medical Association, 285, 3123-3129.

Schulz, R., Mendelson, A. B., \& Haley, W. E. (2003). End-of-life care and the effects of bereavement on family caregivers of persons with dementia. New England Journal of Medicine, 349, 1936-1942.

Schut, H., Stroebe, M. S., van den Bout, J., \& Terheggen, M. (2001). The efficacy of bereavement interventions: Determining who benefits. In M. S. Stroebe, R. O. Hansson, W. Stroebe, \& H. Schut (Eds.), Handbook of bereavement research: Consequences, coping, and care (pp. 705737). Washington, DC: American Psychological Association.

Segal, D. L., Bogaards, J. A., Becker, L. A., \& Chatman, C. (1999). Effects of emotional expression on adjustment to spousal loss among older adults. Journal of Mental Health and Aging, 5, 297-310.

Shaver, P. R., \& Tancredy, C. M. (2001). Emotion, attachment, and bereavement: A conceptual commentary. In M. S. Stroebe, R. O. Hansson, W. Stroebe, \& H. Schut (Eds.), Handbook of bereavement research: Consequences, coping, and care (pp. 63-88). Washington, DC: American Psychological Association.

Shear, K., Frank, E., Houck, P. R., \& Reynolds, C. F., III. (2005). Treatment of complicated grief: A randomized controlled trial. Journal of the American Medical Association, 293, 2601-2608.

Shmotkin, D. (1999). Affective bonds of adult children with living versus deceased parents. Psychology and Aging, 14, 473-482.

Shuchter, S. R. (1986). Dimensions of grief: Adjusting to the death of a spouse. San Francisco, CA: JosseyBass.

Shuchter, S. R., \& Zisook, S. (1993). The course of normal grief. In M. S. Stroebe \& W. Stroebe (Eds.), Handbook of bereavement: Theory, research, and intervention (pp. 23-43). New York: Cambridge University Press.

Silverman, P. R., Baker, J., Cait, C., \& Boerner, K. (2003). The effects of negative legacies on the adjustment of parentally bereaved children and adolescents. Omega: Journal of Death and Dying, 46, 335-352.

Silverman, P. R., Johnson, J., \& Prigerson, H. G. (2001). Preliminary explorations of the effects of prior trauma and loss on risk for psychiatric disorders in recently widowed people. Israel Journal of Psychiatry and Related Sciences, 38, 202-215.

Silverman, P. R., \& Nickman, S. L. (1996). Children's construction of their dead parents. In D. Klass, P. R. Silverman, \& S. L. Nickman (Eds.), Continuing bonds: New understandings of grief (pp. 73-86). Philadelphia: Taylor and Francis.

Silverman, P. R., Nickman, S., \& Worden, J. W. (1992). Detachment revisited: The child's reconstruction of a dead parent. American Journal of Orthopsychiatry, 62, 494-503.

Silverman, P. R., \& Worden, J. W. (1992). Children's reactions in the early months after the death of a parent. American Journal of Orthopsychiatry, 62, 93104.

Smyth, J. M. (1998). Written emotional expression: Effect sizes, outcome types, and moderating variables. Journal of Consulting and Clinical Psychology, 66, 174-184.

Smyth, J. M., \& Greenberg, M. A. (2000). Scriptotherapy: The effects of writing about traumatic events. In P. R. Duberstein \& J. M. Masling (Eds.), Psychodynamic perspectives on sickness and health (pp. 121-160). Washington, DC: American Psychological Association.

Stein, N. L., Folkman, S., Trabasso, T., \& Christopher-Richards, A. (1997). Appraisal and goal processes as predictors of well-being in bereaved care-givers. Journal of Personality and Social Psychology, 72, 863-871.

Stroebe, M. S. (1992-1993). Coping with bereavement: A review of the grief work hypothesis. Omega: Journal of Death and Dying, 26, 19-42.

Stroebe, M. S., Hansson, R. O., \& Stroebe, W. (1993). Contemporary themes and controversies in bereavement research. In M. S. Stroebe, W. Stroebe, \& R. O. Hansson (Eds.), Handbook of bereavement: Theory, research, and intervention (pp. 457-476). Cambridge, England: Cambridge University Press.

Stroebe, M. S., Hansson, R. O., Stroebe, W., \& Schut, H. (Eds.). (2001). Handbook of bereavement research: Consequences, coping, and care. Washington, DC: American Psychological Association.

Stroebe, M., \& Schut, H. (1999). The dual process model of coping with bereavement: Rationale and description. Death Studies, 23, 197-224. 
Stroebe, M. S., \& Schut, H. (2001). Meaning making in the dual process model of coping with bereavement. In R. A. Neimeyer (Ed.), Meaning reconstruction and the experience of loss (pp. 5573). Washington, DC: American Psychological Association.

Stroebe, M., \& Schut, H. (2005). To continue or relinquish bonds: A review of consequences for the bereaved. Death Studies, 29, 477-494.

Stroebe, M., Schut, H., \& Stroebe, W. (2005a). Attachment in coping with bereavement: A theoretical integration. Review of General Psychology, 9, 48-66.

Stroebe, W., Schut, H., \& Stroebe, M. S. (2005b) Grief work, disclosure, and counseling: Do they help the bereaved? Clinical Psychology Review, 25, 395-414.

Stroebe, M., \& Stroebe, W. (1991). Does "grief work" work? Journal of Consulting and Clinical Psychology, 59, 479-482.

Stroebe, M. S., Stroebe, W., \& Hansson, R. O. (Eds.). (1993). Handbook of bereavement: Theory, research, and intervention. New York: Cambridge University Press.

Stroebe, M., Stroebe, W., \& Schut, H. (2001). Gender differences in adjustment to bereavement: An empirical and theoretical review. Review of General Psychology, 5, 62-83.

Stroebe, M., Stroebe, W., \& Schut, H. (in press). Reactions to loss: New directions. Psychological Inquiry.

Stroebe, M., Stroebe, W., Schut, H., Zech, E., \& van den Bout, J. (2002). Does disclosure of emotion facilitate recovery from bereavement? Evidence from two prospective studies. Journal of Consulting and Clinical Psychology, 70, 169-178.

Tedeschi, R. G., \& Calhoun, L. G. (1996). The Posttraumatic Growth Inventory: Measuring the positive legacy of trauma. Journal of Traumatic Stress, 9, 455-472.

Tedeschi, R. G., \& Calhoun, L. G. (2004). Target article: "Posttraumatic growth: Conceptual foundations and empirical evidence." Psychological Inquiry, 15, 1-18.

Teno, J. M., Clarridge, B. R., \& Casey, V. (2004). Family perspectives on end-of-life care at the last place of care. Journal of the American Medical Association, 29, 88-93.

Umberson, D. (1987). Family status and health behaviors: Social control as a dimension of social integration. Journal of Health and Social Behavior, 28, 306-319.

Umberson, D. (1992). Gender, marital status and the social control of health behavior. Social Science and Medicine, 34, 907-917.

Vachon, M. L. S., Rogers, J., Lyall, W. A., Lancee,
W. J., Sheldon, A. R., \& Freeman, S. J. J. (1982). Predictors and correlates of adaptation to conjugal bereavement. American Journal of Psychiatry, 139, 998-1002.

Vachon, M. L. S., Sheldon, A. R., Lancee, W. J., Lyall, W. A. L., Rogers, J., \& Freeman, S. J. J. (1982). Correlates of enduring distress patterns following bereavement: Social network, life situation and personality. Psychological Medicine, 12, 783-788.

Volkan, V. (1971). A study of a patient's "re-grief work" through dreams, psychological tests and psychoanalysis. Psychiatric Quarterly, 45, 244273.

Wayment, H. A., \& Vierthaler, J. (2002). Attachment style and bereavement reactions. Journal of Loss and Trauma, 7, 129-149.

Weiss, R. S. (1993). Loss and recovery. In M. S. Stroebe, W. Stroebe, \& R. O. Hansson (Eds.), Handbook of bereavement: Theory, research, and intervention (pp. 271-284). New York: Cambridge University Press.

Wolff, K., \& Wortman, C. B. (2006). Psychological consequences of spousal loss among the elderly. In D. Carr, R. Nesse, \& C. B. Wortman (Eds.). Spousal bereavement in late life (pp. 81-115). New York: Springer.

Worden, J. W. (2002). Grief counseling and grief therapy: A handbook for the mental health practitioner (3rd ed.). New York: Springer.

Wortman, C. B. (2004). Post-traumatic growth: Progress and problems. Psychological Inquiry, 15, 81-90.

Wortman, C. B., Battle, E. S., \& Lemkau, J. P. (1997). Coming to terms with sudden, traumatic death of a spouse or child. In R. C. Davis \& A. J. Lurigio (Eds.), Victims of crime (pp. 108-133). Thousand Oaks, CA: Sage.

Wortman, C. B., \& Silver, R. C. (1987). Coping with irrevocable loss. In G. R. VandenBos \& B. K. Bryant (Eds.), Cataclysms, crises, and catastrophes: Psychology in action (Master Lecture Series), 6, 189-235. Washington, DC: American Psychological Association.

Wortman, C. B., \& Silver, R. C. (1989). The myths of coping with loss. Journal of Consulting and Clinical Psychology, 57, 349-357.

Wortman, C. B., \& Silver, R. C. (1993). Reconsidering assumptions about coping with loss: An overview of current research. In S. H. Filipp, L. Montada, \& M. Lerner (Eds.), Life crises and experiences of loss in adulthood. Hillsdale, NJ: Erlbaum.

Wortman, C. B., \& Silver, R. C. (2001). The myths of coping with loss revisited. In M. S. Stroebe, R. O. Hansson, W. Stroebe, \& H. Schut (Eds.), Handbook of bereavement research: Consequences, 
coping, and care (pp. 405-430). Washington, DC: American Psychological Association.

Wortman, C. B., Wolff, K., \& Bonanno, G. (2004).

Loss of an intimate partner through death. In D. Mashek \& A. Aron (Eds.) The handbook of closeness and intimacy. Mahwah, NJ: Erlbaum.

Zisook, S., Chentsova-Dutton, Y., \& Shuchter, S. R. (1998). PTSD following bereavement. Annals of Clinical Psychiatry, 10, 157-163.
Zisook, S., Paulus, M., Shuchter, S. R., \& Judd, L. L. (1997). The many faces of depression following spousal bereavement. Journal of Affective Disorders, 45, 85-94.

Zisook, S., \& Shuchter, S. R. (1986). The first four years of widowhood. Psychiatric Annals, 16, 288-294.

Zisook, S., \& Shuchter, S. R. (1993). Major depression associated with widowhood. American Journal of Geriatric Psychiatry, 1, 316-326. 